IZA DP No. 10265

Frictional Unemployment with Stochastic Bubbles

Guillaume Vuillemey

Etienne Wasmer

October 2016 


\title{
Frictional Unemployment with Stochastic Bubbles
}

\author{
Guillaume Vuillemey \\ HEC Paris \\ Etienne Wasmer \\ Sciences-Po, LIEPP and IZA
}

\section{Discussion Paper No. 10265 \\ October 2016}

\author{
IZA \\ P.O. Box 7240 \\ 53072 Bonn \\ Germany \\ Phone: +49-228-3894-0 \\ Fax: +49-228-3894-180 \\ E-mail: iza@iza.org
}

\begin{abstract}
Any opinions expressed here are those of the author(s) and not those of IZA. Research published in this series may include views on policy, but the institute itself takes no institutional policy positions. The IZA research network is committed to the IZA Guiding Principles of Research Integrity.

The Institute for the Study of Labor (IZA) in Bonn is a local and virtual international research center and a place of communication between science, politics and business. IZA is an independent nonprofit organization supported by Deutsche Post Foundation. The center is associated with the University of Bonn and offers a stimulating research environment through its international network, workshops and conferences, data service, project support, research visits and doctoral program. IZA engages in (i) original and internationally competitive research in all fields of labor economics, (ii) development of policy concepts, and (iii) dissemination of research results and concepts to the interested public.
\end{abstract}

IZA Discussion Papers often represent preliminary work and are circulated to encourage discussion. Citation of such a paper should account for its provisional character. A revised version may be available directly from the author. 
IZA Discussion Paper No. 10265

October 2016

\section{ABSTRACT}

\section{Frictional Unemployment with Stochastic Bubbles*}

Bubbles are recurrent events, which contribute to both macroeconomic and employment volatility. We introduce stochastic bubbles in the standard search-and matching model of the labor market. The economy alternates between latent and bubbly states, each being associated with a distinct solution for the market value of firms (respectively, stable or explosive). Bubbles in firm value induce distortions in hiring decisions and wages, which we explicitly characterize. Faced with bubbles, the social planner optimally deviates from the standard Hosios efficiency condition. The optimal share of workers in total surplus must be above the elasticity of hiring rates, by a small but increasing amount as the bubble expands. Finally, our specification for bubbles significantly improves the quantitative ability of the model to match U.S. data, along both real and financial dimensions.

JEL Classification: E32, J60

Keywords: unemployment volatility, labor frictions, bubbles

Corresponding author:

Etienne Wasmer

Sciences-Po Paris

Departement d'Economie

28 Rue des Saint-Pères

75007 Paris

France

E-mail: etienne.wasmer@sciences-po.fr

\footnotetext{
* We are grateful to Edouard Challe, Wouter den Haan, Christopher Pissarides, Guillaume Rocheteau, Jean Tirole and Philippe Weil for very useful discussions, and to participants at the 2016 SaM conference (Amsterdam), and the OFCE-SKEMA conference (Nice), in particular Maurizio lacopetta, Espen Moen, Alessandra Pelloni, Christophe Pérignon, Jean-Marc Robin and Coen Teulings.
} 


\section{NON-TECHNICAL SUMMARY}

Recent research has renewed the interest in bubbles as potentially important determinants of business cycles. Several decades have been characterized by recurrent episodes of high financial volatility. Examples include the Black Monday crash of 1987, the Dot-com bubble of 1999-2000, and the stock market crash of 2008-2009. Between October 2007 and March 2009, the decline in the Dow Jones was $-53.9 \%$. The repeated rise and fall of firm market values can hardly be attributed only to technological innovations. Instead, these episodes are often described as economy-wide changes in beliefs, and referred to as "bubbles".

The connection between financial fluctuations and employment is important but still lacks a consensus. We focus here on bubbles as an alternative source of financial fluctuations. As we document in the text, bubbly episodes strongly correlate with fluctuations in labor market outcomes and have thus the potential to explain unemployment volatility. Although bubbles are hard to disentangle from fundamentals in the data, financial markets fluctuations can easily be connected to the appearance and burst of bubbles: in particular bubbles are more likely to appear when agents discount at low rates of interest.

Our first contribution is to bring back bubbles as explosive solutions to the standard labor matching model. We do so in a setup which is both analytically tractable and consistent with the data. In particular, bubbly episodes in our model are temporary. We define two states: the latent and the bubbly states. The economy alternates between these states according to a stochastic process. In the latent state, expectations of all agents are coordinated on a stable path. In the bubbly state, the asset values grow at the only rate consistent with rational expectations.

The second contribution is to explore the implications of such bubbles on unemployment volatility. Unemployment and labor market tightness are far more volatile in the data than in the model. We highlight a new "financial volatility puzzle", namely the fact that financial variables implied by the standard model, such as the market value of firms or the priceearnings ratio, also exhibit low volatility. We provide evidence that the two puzzles are linked. Allowing for bubbles significantly improves the ability of the model to replicate U.S. data.

The third contribution is to explore the normative implications of bubbles. Distortions induced by bubbles can either improve or reduce efficiency in their early phase. If the economy starts in the steady-state at an efficient level of unemployment, as bubbles expand, distortions magnify, and bubbles are socially undesirable, even though they temporarily reduce unemployment. 


\section{Introduction}

Recent decades have been characterized by recurrent episodes of high financial volatility. Examples, illustrated in Figure 1, include the Black Monday crash of 1987, the Dot-com bubble of 1999-2000, and the stock market crash of 2008-2009. Between October 2007 and March 2009, the decline in the Dow Jones was $-53.9 \%{ }^{1}$ The repeated rise and fall of firm market values can hardly be attributed only to technological innovations. Instead, these episodes are often described as economy-wide changes in beliefs, and referred to as "bubbles".

The connection between financial fluctuations and employment is important but still lacks a consensus. Hall (2016) argues that the sources of fluctuation in employment in the canonical search-and-matching model of the labor market are yet unresolved and that the most promising explanation comes from fluctuations in the discount rate. We focus here on bubbles as an alternative source of financial fluctuations. As we document in the next section, bubbly episodes strongly correlate with fluctuations in labor market outcomes and have thus the potential to explain unemployment volatility. Although bubbles are hard to disentangle from fundamentals in the data, financial markets fluctuations can easily be connected to the appearance and burst of bubbles: in particular bubbles are more likely to appear when agents discount at low rates (Caballero, 2006), fitting the insights in Hall (2016) of disproportionate inflation of real variables after an episode of low discounting.

Recent important papers have renewed the interest in bubbles as potentially important determinants of business cycles. Martin and Ventura (2012) and Carvelho, Martin, and Ventura (2011) develop a view of bubbles driven by investors' sentiments and study their quantitative properties. $^{2}$ Further, as Fahri and Tirole (2012) show, bubbles may be sustainable in a broader range of models than initially thought. In particular, in the

\footnotetext{
${ }^{1}$ There are also a number of trading days in which large changes in asset prices are hard to justify by changes in fundamentals only, and can be best explained by changes in beliefs. For example, the S\&P 500 fell by $8.81 \%$ on September 29, 2008 and by $9.03 \%$ on October 15, 2008.

${ }^{2}$ See also Ljungqvist and Wilhelm (2003); Ofek and Richardson (2003); Brunnermeier and Nagel (2004) for the Dot-come bubble. Kindleberger (1978) provides a detailed account of a number of other historical episodes typically considered as bubbles.
} 
presence of imperfect capital markets, bubbles can arise even if the economy is dynamically efficient, in contrast with results obtained in models with perfect markets.

Figure 1 - S\&P Composite Index, 1970-2016

This figure plots the S\&P Composite Index over the 1970-2016 period. Data in the left and right panels are, respectively, in nominal and real terms. See Appendix A for details on the data.
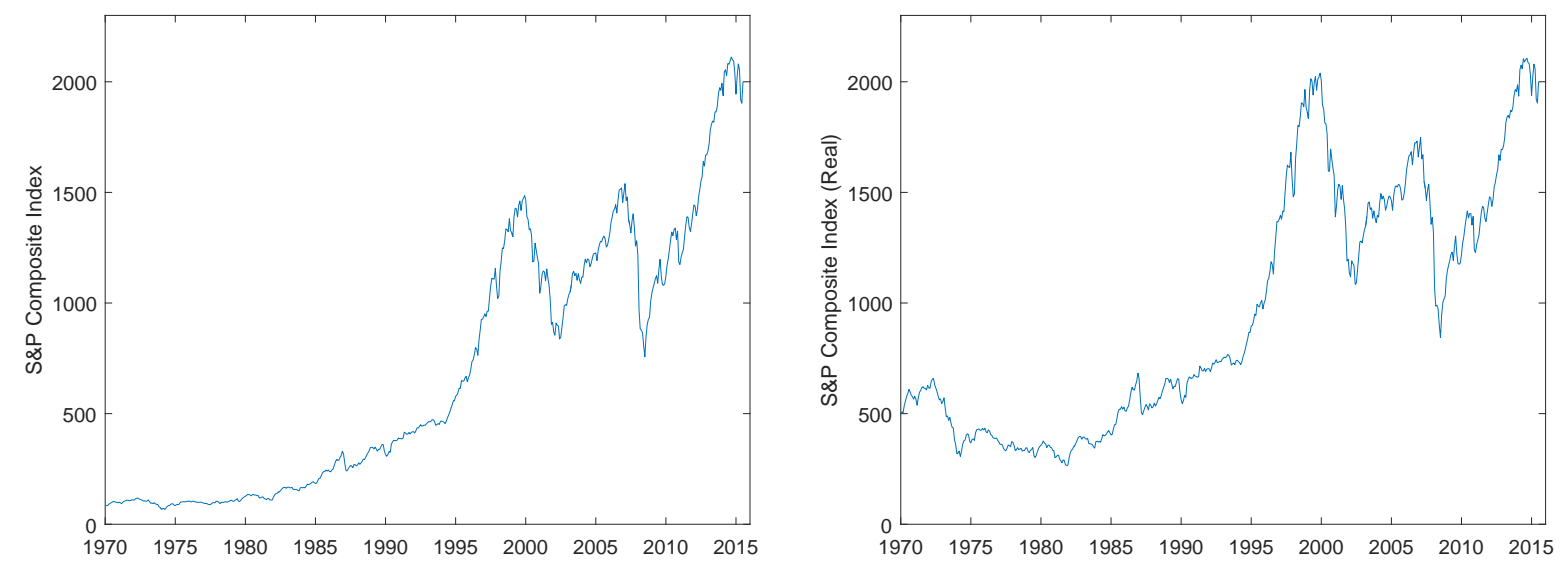

In this paper, we introduce bubbles in the standard search-and-matching model of the labor market (Pissarides, 1985, 2000). In the simplest single-worker firm, the asset value of a filled vacancy solves a Bellman equation. It equals profits to be earned at the current date, plus the expected firm value at the beginning of next period. The latter term depends on expectations about capital gains, that is, per-period changes in the firm's market value. One particular solution is the fundamental value, i.e., firm value always equals the present discounted value of future profits. There are, however, an infinite number of other solutions, associated with divergent expectations. Imposing transversality conditions, these other solutions, or bubbles, can be ruled out (Pissarides, 2000). Existing works have therefore restricted attention to the unique stable path. Nonetheless, as Blanchard and Fischer (1989, Chapter 5) highlight, ruling out bubbles relies "on a degree of rationality and foresight that is unlikely to be present in practice."

Our first contribution is to bring back these explosive solutions to the standard labor matching model. We do so in a setup which is both analytically tractable and consistent with the data. In particular, bubbly episodes in our model are temporary. We define two states: the latent and the bubbly states. The economy alternates between these 
states according to a stochastic process which is common knowledge. In the latent state, expectations of all agents are coordinated on a stable path, as in Pissarides (2000). In the bubbly state, the asset values grow at the only rate consistent with rational expectations. Transitions between states follow a Poisson process.

The second contribution is to explore the implications of such bubbles in the matching model. Compared to the model by Pissarides $(1985,2000)$, in which all equilibrium values are fundamental values, bubbles induce distortions in market tightness, hiring decisions, and wages. We characterize these distortions in closed-form. In the latent state, where divergent expectations do not exist but may appear stochastically, we find that equilibrium values of labor market variables are not equal to fundamental values. This is because the value of filled vacancies incorporates the present value of capital gains due to future bubbles. Distortions amplify in the bubbly state, as the gap between the value of filled and unfilled vacancies widens over time. Firms post more vacancies. The tightness of the labor market increases, unemployment decreases, and wages increase. These predictions are consistent with stylized facts about bubbles.

From a normative viewpoint, distortions induced by bubbles can either improve or reduce efficiency in their early phase. On the one hand, if the economy starts in the steady-state at an efficient level of unemployment, as bubbles expand, distortions magnify, and bubbles are socially undesirable, even though they temporarily reduce unemployment. Jobs are created even though they generate low, or even negative, real profits. In that case, to correct the allocative distortions induced by bubbles, the social planner optimally deviates from the standard Hosios efficiency condition (Hosios, 1990), according to which the workers' share of surplus within matches internalizes their congestion externality in the search process. Here, the social planner wants to mitigate congestion externalities, but also to lower investors' expectations about future capital gains from the bubble. It does so by optimally increasing the workers' share of surplus above the matching elasticity parameter (reflecting the congestion effect), but also eventually, when bubbles have lasted for too long, by setting the workers' share of surplus above one. This modified Hosios rule is a temporary one, depending on the time elapsed since the bubble appearance. 
On the other hand, under the "small surplus assumption" (Hagedorn and Manovskii, 2008), where the actual share of workers largely exceeds the efficient value implied by the matching externality, then bubble expansion reduces inefficiencies, at least temporarily, until the modified Hosios rule is reached.

Quantitatively, using our calibration, the deviation from the Hosios rule is small when the bubble starts, but continuously increases as the bubble expands. The optimal share of workers in total surplus could even reach 1 after 27 quarters. We remain silent on how the share of workers could be affected by the social planner, but instruments such as tax on wages or subsidies to non-employment, as well as direct actions on labor market tightness - such as a taxes on vacancies - could be used.

A third contribution is to show that allowing for bubbles significantly improves the ability of the matching model to replicate U.S. data. It is indeed well-known that common calibrations of the model give rise to an unemployment volatility puzzle (Shimer, 2005; Pissarides, 2009): unemployment and labor market tightness are far more volatile in the data than in the model. We highlight a new "financial volatility puzzle", namely the fact that financial variables implied by the standard model, such as the market value of firms or the price-earning ratio, also exhibit low volatility. We provide evidence that the two puzzles are linked. Indeed, we document strong co-movement between the stock market valuation of firms and labor market outcomes, both at the sector level and at the aggregate level.

We show that allowing for stochastic bubbles can jointly rationalize high financial and labor market volatility. In our quantitative exercise, we calibrate all parameters related to the labor market as in Shimer (2005). Parameters governing bubbles are set based on financial data, such as the frequency and average duration of stock price bubbles. Simulated volatilities of the job finding rate and of market tightness are close to their empirical counterparts. Therefore, bubbles have the potential to jointly solve the unemployment volatility and the financial volatility puzzles. 


\section{Interpretation of bubbles}

There is a large literature on bubbles, which we summarize in greater detail in Section 8 . Here, we describe the relation between our model of bubbles and existing specifications. First, our model is kept as close to full rationality as possible. For example, the expected return of holding the bubble is equal to the risk-free rate, in line with Tirole (1982, 1985) and Blanchard and Watson (1982). The Poisson process leading to a bubbly state corresponds to the appearance of a positive mass of agents believing in explosive capital gains. These agents have the ability to buy assets at their new price, even if they rationally anticipate that the bubble will eventually burst. Hence, the existence condition for a bubble is the presence of a mass of agents believing in the bubbly solution and facing no cash limit, nor expecting any cash limit to bind in the future. Furthermore, no other agent is able to immediately short sell the bubble and make it collapse. ${ }^{3}$

These assumptions make it possible to solve one difficulty with rational bubbles: for rational bubbles to exist, they must logically have existed forever, as clearly stated in Weil (1987) and Diba and Grossman (1988). This is because forward-looking agents, rationally expecting today's value, must have bought the bubble at a price consistent with today's price at any point in the past. Ever-growing bubbles are at odds with historical evidence. Instead, a bubble is always present in our model, but the succession of latent and bubbly states limits the perpetual growth of bubble. Hence, the bubble can have been present since the first day of trading, still exist and be finite at any date.

Symmetrically, the random Poisson event inducing bubbly expectations to end can be interpreted as the disappearance of the mass of agents believing in the bubbly solution, or as resulting from credit constraints or from a change in beliefs by these agents. When this occurs, the firm goes back to the latent state. In our model, we let latent and bubbly solutions exist sequentially, and both survive for a random number of periods.

Our model shares features of a perpetual youth model à la Blanchard and Fischer (1989, Chapter 3) on firms' side: agents owning the bubbly asset periodically die at a

\footnotetext{
${ }^{3}$ Another interpretation is that there is temporary coordination of all agents on one bubbly solution for firm value. This interpretation is consistent with empirical evidence according to which aggregate investor sentiment can drive bubbles (Baker and Wurgler, 2006, 2007).
} 
constant rate due to the obsolescence of the firm. This is an idiosyncratic event which dissipates the firm's value. In a steady-state, they are replaced by agents starting new businesses to satisfy a free-entry condition. These population inflows and outflows reduce the accumulation of wealth in the economy, as in an OLG setup.

Another issue pertains to the perception of bubbles by agents. If the bubble could last forever, agents would not believe into it if they knew that the bubble would disappear with certainty due to some feasibility constraint. In our setup, agents know that any bubbly episode will stochastically end, and this happens with probability approaching one exponentially. However, it is still rational to buy or keep the asset associated with the bubble. The only requirement is a feasibility constraint: agents believe that there will be buyers as long as the bubbly regime lasts. One possible rationalization is that, even for a large bubble, monetary authorities commit to supplying the liquidity needed to sustain it as long as the bubbly state exists, a situation that may resemble current episodes of monetary policy.

The assumptions that agents may misperceive the feasibility constraint, may have different expectations about bubbles but cannot engage in short-selling if they are nonbelievers (in the bubble), and that firms may periodically disappear, are sufficient for bubbles to exist in our infinite-horizon model. In contrast, Tirole (1982) derived conditions under which bubbles can be ruled out. Our assumptions are needed to bring back bubbles in search-and-matching models in a tractable way. ${ }^{4}$

\section{Organization of the paper}

We proceed as follows. Section 2 documents facts that motivate the specification of the model. Section 3 describes the model with fixed wages, while Section 4 endogenizes wages. Section 5 discusses first-best and second-best efficiency. We extend the model to productivity shocks in Section 6 and calibrate it and report simulation results in Section 7. Section 8 relates the paper to the literature.

\footnotetext{
${ }^{4}$ We view these assumptions as a convenient shortcut for the financial imperfections sustaining bubbles, as emphasized in Fahri and Tirole (2012).
} 


\section{Facts and the "financial volatility puzzle"}

Before turning to the model, we present facts that motivate our introduction of bubbles in the search-and-matching model. In particular, we discuss the relation between labor and financial market volatilities in the conventional model and in U.S. data, and document a financial volatility puzzle.

\subsection{Labor and financial market volatility: Empirical evidence}

We start with sectoral evidence of the relation between bubbles and employment. In Panel A of Figure 2, we illustrate the bubble on technology stocks at the end of the 1990s. ${ }^{5}$ We superimpose the Nasdaq (index for technology stocks) with the Dow Jones Industrial Average (general index) over the 1995-2005 period, after normalizing each index to 100 in 1995. The market valuation of technology stocks relative to other stocks increased considerably in the months leading up to the March 2000 crash. We interpret this event as a sectoral bubble. In the context of the Pissarides model, this corresponds to a sharp increase in the market value of firms in the technology sector.

Turning to labor market outcomes, we plot in Panel B the level of U.S. employment in the technology sector and in other sectors over the same period. The left figure shows that the total number of workers employed in the technology sector (normalized to 100 in January 1995) increased at a faster pace than the number of workers in other sectors in the years leading to 2000 crash. After 2000, it decreased back to a level similar to that of the pre-bubble period. To isolate differences in employment trends in the technology and in other sectors from cyclical labor market outcomes correlated with the bubble, we detrend employment series in the right figure of Panel B. Focusing on the cyclical component of employment makes it evident that large deviations from the aggregate trend occurred at the time the market valuation of technology firms increased relative to that of nontechnology firms. Therefore, sectoral fluctuations in the stock market are closely linked

\footnotetext{
${ }^{5}$ To illustrate our argument, the technology bubble is more relevant than housing bubbles. Housing bubbles are typically bubbles on land, not on firm value as such. The fact that the rise and fall of technology stocks in the 1990s is due to a bubble is widely acknowledged, see footnote 2.
} 
to the dynamics of labor market variables.

Wages exhibit a different pattern over the same period. In Panel C, wages in the technology sector and in other sectors are plotted, both in levels (normalized to 100 in January 1995, left figure) and in log-deviation from trend (right figure). As can be seen, wages do not exhibit strong deviations from trend in the technology sector during the bubble. ${ }^{6}$ In this respect, evidence suggests that labor market adjustments during bubbles occur primarily through quantities rather than through prices.

Finally, a tight connection between the stock market valuation of firms and labor market outcomes is also observed at the aggregate level, over the post-war period. In Panel A of Figure 3, we plot the HP-filtered log-level of the S\&P Composite Stock Price Index, obtained from Shiller (2015), together with the U.S. unemployment rate, over the 1951-2014 period. A strong negative relation between the two series is observed: unemployment is low at times stock market valuations are high, and vice versa. Over this period, the pairwise correlation between both series is -0.53 .

\subsection{Financial volatility in the standard matching model}

Next, we revisit the argument according to which the matching model (Pissarides, 1985, 2000), using standard parameter values, does not generate a high enough volatility of unemployment and labor market tightness (Shimer, 2005). We summarize this discussion in Table 1. In Panel A, we compute the log standard deviation of several labor market variables in U.S. data, over the 1951-2014 period. ${ }^{7}$ These variables include unemployment, vacancies, labor market tightness and the job finding rate (see Appendix A for details on the data used). Labor productivity has a log standard deviation of 0.020, while labor market tightness has a log standard deviation of 0.371. In Panel B, we compute the same moments based on simulations of the Pissarides model, and using the calibration by

\footnotetext{
${ }^{6}$ Our wage data may underestimate the impact of bubbles on wages, since it concentrates on production and nonsupervisory employees (see Appendix A for details). As such, it excludes executive compensation, which is more likely to be sensitive to bubbles in firm value. Indeed, a sizable share of executive compensation is often tied to the firm's stock price.

${ }^{7}$ For consistency with the literature, we follow Shimer (2005) by converting all variables at a quarterly frequency and HP-filtering them with a smoothing parameter equal to 100,000. Standard deviations are from HP trends.
} 
Shimer (2005). We obtain a log standard deviation of 0.035 for labor market tightness, i.e., about ten times lower than in the data. Other variables, such as unemployment or the job finding rate, are also an order of magnitude less volatile in the model than in the data.

We also report financial moments simulated from the same model. The log standard deviation of firm market value equals 0.017 , and is relatively close to the volatility of labor productivity (equal to 0.020). Computed using the S\&P Composite Index over the 1951-2014 period, the same moment equals 0.151 in the data. The market valuation of firms is about eight times more volatile in the data than in the model. Therefore, both real and financial variables lack volatility in the standard model.

We finally compare the price-earning $(\mathrm{P} / \mathrm{E})$ ratio in the model and in the data. Focusing on the $\mathrm{P} / \mathrm{E}$ ratio makes it possibly to assess the volatility of market prices relative to that of fundamentals. We obtain a time series of the cyclically adjusted $\mathrm{P} / \mathrm{E}$ ratio, computed using the S\&P Composite Index, from Robert Shiller's website (see Appendix A for details). ${ }^{8}$ In the matching model, we compute the same $\mathrm{P} / \mathrm{E}$ ratio, where prices are the market value of firms and earnings the difference between output and wages. The log standard deviation of the $\mathrm{P} / \mathrm{E}$ ratio equals 0.161 in the data. In contrast, it is eleven times less volatile in the model (log standard deviation of 0.015 ), and close to the volatility of labor productivity (equal to 0.020). We conclude that a large part of fluctuations in stock market prices in the data are not driven by changes in earnings. Therefore, turning to the model, the lack of volatility of fundamentals is not sufficient to explain the lack of volatility of stock market valuations. ${ }^{9}$ Additional intuition can be gained by noticing, in Panel B of Figure 3, that empirical fluctuations in the $\mathrm{P} / \mathrm{E}$ ratio closely track fluctuations in the stock market (Panel A). These facts suggest that a large part of financial volatility is not directly attributable to the volatility of earnings.

\footnotetext{
${ }^{8}$ Results are consistent, however more noisy, when using a plain $\mathrm{P} / \mathrm{E}$ ratio. Noise arises from a welldocumented drawback of the $\mathrm{P} / \mathrm{E}$ ratio. Following drops in earnings during recessions, the $\mathrm{P} / \mathrm{E}$ ratio is artificially inflated when earnings are low or close to zero. Shiller performs a cyclical adjustment by averaging earnings over a moving period of 10 years.

${ }^{9}$ Starting with Shiller (1981), a number a papers have argued that the volatility of stock prices cannot be explained by the volatility of dividends.
} 
Since stock market prices have a high volatility in the data, even though the fundamental drivers of asset prices (i.e., earnings) have a low volatility, a model is which all decisions and valuations are driven by changes in earnings is unlikely, by construction, to replicate empirical volatilities. We see this fact as a new challenge to the standard model, and call it the financial volatility puzzle.

This section has highlighted four facts. First, data at both the sector level and the aggregate level show a close connection between financial markets and labor markets. Second, the noted fact that the standard matching model cannot replicate the high volatility of labor markets is the reflection of its inability to replicate the high volatility of financial market variables. The introduction of a channel giving rise to volatile market prices in the absence of volatile fundamentals is therefore needed. Third, non-fundamental changes in the market value of firms (bubbles) play a role in jointly explaining the high financial and labor market volatility. ${ }^{10}$ Last, adjustments in the labor market during bubbly episodes arise mostly through quantities, not wages.

\footnotetext{
${ }^{10}$ The fact that, even in the absence of bubbles, financial markets have a potential role to play in explaining unemployment fluctuations, has been developed in a recent paper by Hall (2016), where financial market-driven changes in discount rates affect hiring decisions. While changes in discount rates have the potential to explain the aggregate dynamics, they cannot rationalize sectoral shifts in the market valuation of firms, as we document in the case of the technology bubble.
} 


\section{Table 1 - Data versus Pissarides model moments}

This table compares labor and financial market moments in the data (Panel A) and in the Pissarides model with fully flexible wages (Panel B). $u$ denotes unemployment, $v$ the number of vacancies, $\theta$ the labor market tightness, $f$ the job finding rate, $x$ labor productivity, $J$ the market value of firms and $J /(x-w)$ the price-earning ratio. Data is at a quarterly frequency, over the 1951-2015 period. Whenever needed, quarterly variables are computed by averaging monthly variables. Financial moments are computed using the S\&P Composite Index. The model is calibrated using the parameter values suggested by Shimer (2005) and summarized in Table 2. All variables, both in data and model, are reported is logs as deviations from an HP trend with smoothing parameter 100,000. Persistence refers to the autocorrelation of growth rates. Details on the construction of the data series are provided in Appendix A.

\begin{tabular}{|c|c|c|c|c|c|c|c|c|}
\hline \multicolumn{9}{|c|}{ Panel A: Data — 1951-2014 } \\
\hline & & \multicolumn{5}{|c|}{ Labor market moments } & \multicolumn{2}{|c|}{ Financial moments } \\
\hline & & $u$ & $v$ & $\theta$ & $f$ & $x$ & $J$ & $J /(x-w)$ \\
\hline Standard deviation & & 0.200 & 0.187 & 0.371 & 0.136 & 0.020 & 0.151 & 0.161 \\
\hline Autocorrelation & & 0.948 & 0.943 & 0.947 & 0.935 & 0.897 & 0.923 & 0.931 \\
\hline \multirow[t]{4}{*}{ Persistence } & & 0.588 & 0.634 & 0.670 & 0.120 & 0.102 & 0.333 & 0.350 \\
\hline & $u$ & 1 & -0.875 & -0.964 & -0.950 & -0.330 & -0.485 & -0.493 \\
\hline & $v$ & - & 1 & 0.970 & 0.826 & 0.359 & 0.431 & 0.448 \\
\hline & $\theta$ & - & - & 1 & 0.913 & 0.356 & 0.468 & 0.483 \\
\hline \multirow[t]{7}{*}{ Correlation matrix } & $f$ & - & - & - & 1 & 0.327 & 0.535 & 0.505 \\
\hline & $x$ & - & - & - & - & 1 & 0.178 & 0.335 \\
\hline & $J$ & - & - & - & - & - & 1 & 0.938 \\
\hline & $J /(x-w)$ & - & - & - & - & - & - & 1 \\
\hline & & \multicolumn{5}{|c|}{ Panel B: Pissarides model } & & \\
\hline & & \multicolumn{5}{|c|}{ Labor market moments } & \multicolumn{2}{|c|}{ Financial moments } \\
\hline & & $u$ & $v$ & $\theta$ & $f$ & $x$ & $J$ & $J /(x-w)$ \\
\hline Standard deviation & & 0.015 & 0.025 & 0.035 & 0.020 & 0.020 & 0.017 & 0.018 \\
\hline Autocorrelation & & 0.914 & 0.595 & 0.826 & 0.826 & 0.838 & 0.383 & 0.297 \\
\hline Persistence & & 0.270 & -0.277 & -0.081 & -0.081 & -0.044 & -0.044 & -0.458 \\
\hline \multirow{7}{*}{ Correlation matrix } & $u$ & 1 & -0.534 & -0.773 & -0.773 & -0.779 & -0.777 & -0.599 \\
\hline & $v$ & - & 1 & 0.950 & 0.949 & 0.938 & 0.943 & 0.864 \\
\hline & $\theta$ & - & - & 1 & 0.999 & 0.993 & 0.997 & 0.872 \\
\hline & $f$ & - & - & - & 1 & 0.993 & 0.997 & 0.872 \\
\hline & $x$ & - & - & - & - & 1 & 0.999 & 0.873 \\
\hline & $J$ & - & - & - & - & - & 1 & 0.874 \\
\hline & $J /(x-w)$ & - & - & - & - & - & - & 1 \\
\hline
\end{tabular}


Figure 2 - Stock market valuation, employment and wages: the whole economy and the technology sector, 1995-2005

Panel A depicts a sectoral stock market bubble. It plots two stock market indices, the Dow Jones Industrial Average and the Nasdaq Composite Index over the 1995-2005 period ("technology bubble"). The Nasdaq is concentrated on technology firms while the DJIA is a general index. We normalize both series to 100 in January 1995. Panel B plots employment in the technology sector and in all other sectors over the same period. The left figure plots the total number of employed workers, normalized to 100 in January 1995. The right figure plots the same variables in log deviations from trends. Panel C plots hourly earnings in the technology sector and in all other sectors over the same period. The left figure plots the level of hourly earnings, normalized to 100 in January 1995. The right figure plots the same variables in log deviations from trends. Trends are obtained using an HP filter with smoothing parameter equal to 100,000. Details on the construction of the data series are provided in Appendix A.

Panel A: Stock market bubble in the technology sector

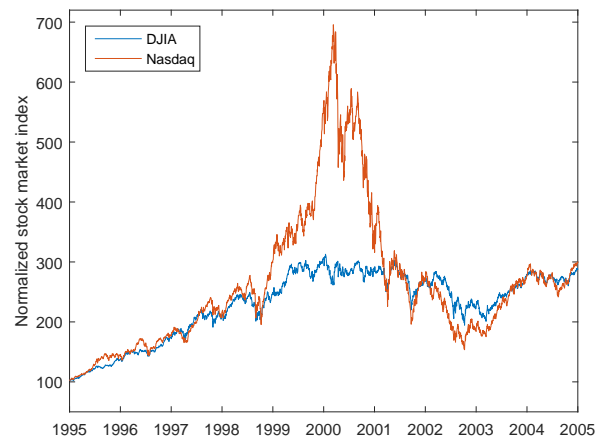

Panel B: Employed workers in the technology sector
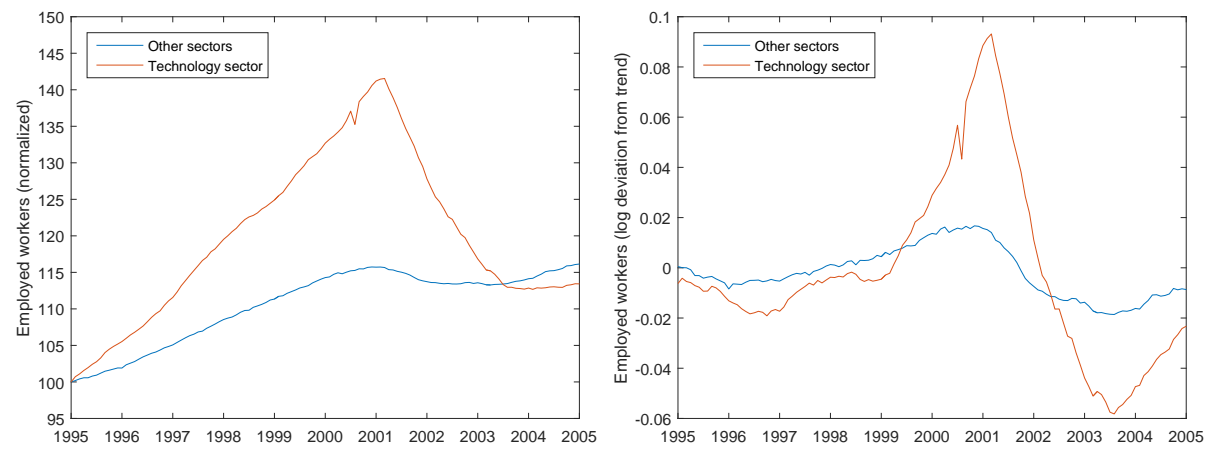

Panel C: Hourly earnings in the technology sector
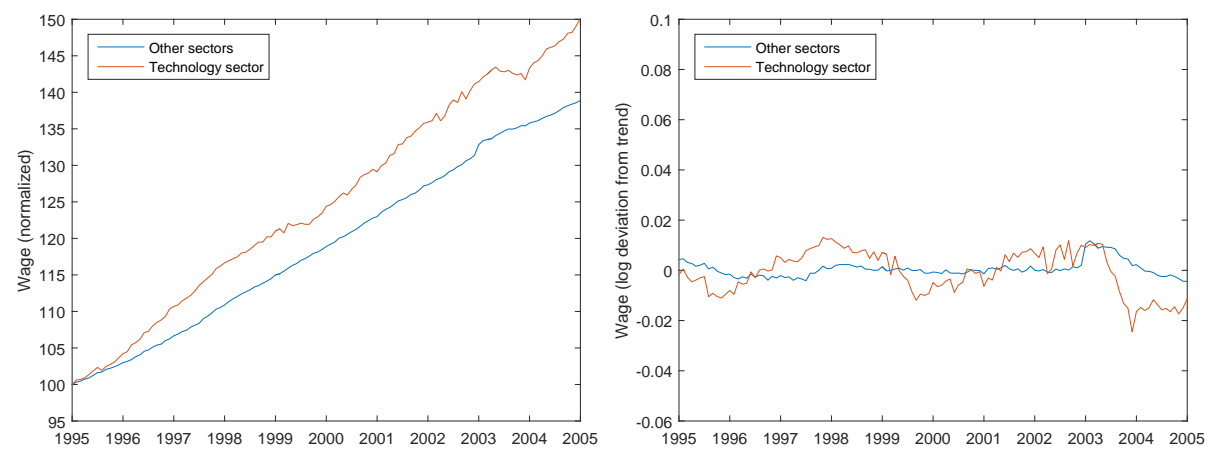
Figure 3 - Aggregate stock market valuation and unemployment

Panel A plots the U.S. stock market valuation (left axis) and unemployment (right axis) over the period from 1951Q1 to 2014Q4. Panel B plots the cyclically adjusted price-earning ratio (left axis) and unemployment (right axis) over the same period. Stock market data is for the S\&P Composite Stock Price Index. For the stock market level and $\mathrm{P} / \mathrm{E}$ ratio, we show cyclical variation obtained by HP-filtering the $\log$ of these variables, with smoothing parameter equal to 100,000. Unemployment is in percentage of the labor force. NBER recession periods are shaded. Details on the construction of the data series are provided in Appendix A.

Panel A: Stock market level and unemployment

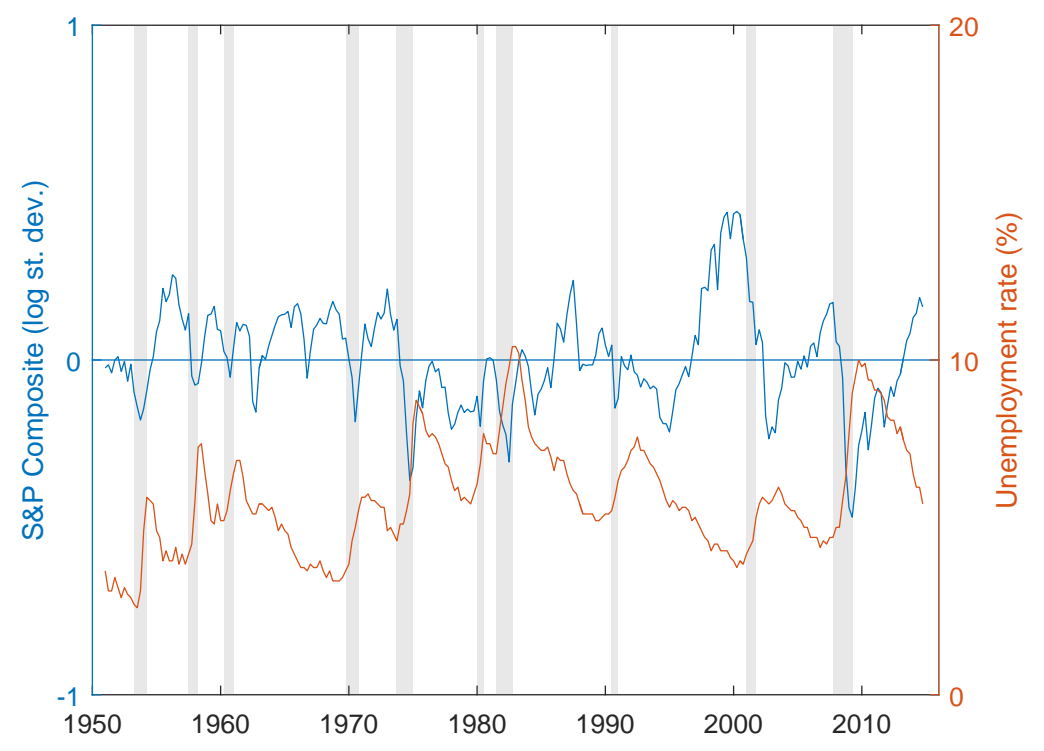

Panel B: Price-earning ratio and unemployment

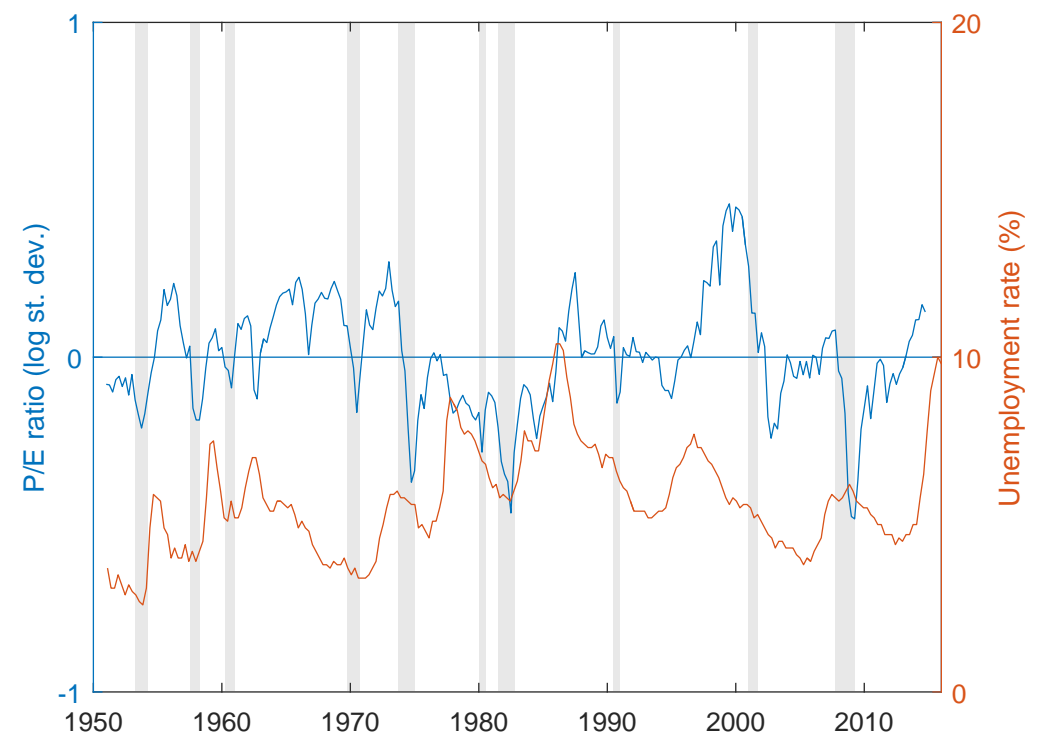




\section{Bubbles in a one-sector economy}

Next, we show that allowing for bubbly solutions in the matching model allows replicating the above facts. We start by exposing the notation of the Pissarides (1985, 2000) model. Then, bubbles on firm value are introduced. In a first part, we treat wages as parameters for the firm and derive the main concepts of entry and bubbles. Next, we consider bargaining on wages and equilibrium.

Thereafter, we describe three distinct cases. The first one, referred to as fundamental, is the Pissarides model, in which there are no bubbles, and bubbles cannot arise. The two other cases are those in which a bubble exists and is always present. However, the bubble can either be latent or expanding. In the latent state, asset values are stationary, but the economy can shift stochastically to an expanding state. In the expanding state, called the bubbly state, firm value grows exponentially, but can explode at any time, so that the economy returns to the latent state. Importantly, the bubble exists in both the latent and the bubbly states, in the sense that the firm's value is always above its fundamental value.

\subsection{The fundamental search economy}

Time is continuous. Equilibrium values obtained in this section are fundamental values, since they exclude the possibility of bubbles. Consider a measure one of risk-neutral agents discounting future cash flows at rate $r>0$. At a given point in time, $v$ vacant positions exist, $n$ workers are employed and $u=1-n$ are unemployed and looking for jobs. We model infinitely-lived single-worker firms. For notational convenience, time subscripts are dropped.

The tightness of the labor market is defined by $\theta=v / u$. We assume the existence of a matching function $m(v, u)$ with constant returns to scale. The number of matches $m$ between vacant jobs and unemployed workers formed per unit of time satisfies the identity

$$
m=q v=f u
$$


where $q$ is the job filling rate and $f$ the job finding rate. With constant returns to scale in the matching function, they satisfy, respectively,

$$
q(\theta)=\frac{m(v, u)}{v} \text { and } \quad f(\theta)=\frac{m(v, u)}{u}=\theta q(\theta)
$$

Existing jobs are destroyed at an exogenous rate $s>0$, yielding the law of motion of unemployment

$$
\frac{\partial u}{\partial t}=s(1-u)-\theta q(\theta) u
$$

Exogenous separation can be interpreted as resulting from real shocks associated with shifts in preferences of technology.

When opening and keeping a vacancy unfilled, a firm incurs posting costs $\gamma>0$ per unit of time. After a firm is matched with a worker, the match yields a constant per-period output flow $x$, which we interpret as labor productivity. In our quantitative exercise, we later assume a Markov process for productivity. Furthermore, $x$ is assumed to exceed the value of unemployment benefits $z>0$, so that there are bilateral gains from matching. ${ }^{11}$ The firm pays an employed worker a per-period wage $w$, and earns a profit flow $x-w$. Denote $J^{0}$ and $J_{v}^{0}$ the asset values for filled and unfilled vacancies in the fundamental state. They write recursively as

$$
\begin{aligned}
& r J^{0}=x-w+s\left(J_{v}^{0}-J^{0}\right)+\frac{\partial J^{0}}{\partial t} \\
& r J_{v}^{0}=-\gamma+q(\theta)\left(J^{0}-J_{v}^{0}\right)+\frac{\partial J_{v}^{0}}{\partial t}
\end{aligned}
$$

At the steady state, and in the absence of bubble, the time derivatives in (2) and (3) are equal to zero. Assuming free-entry of vacancies, $J_{v}^{0}=0$. Equilibrium firm entry in the labor market is such that entry costs and future profits are equalized,

$$
J^{0}=\frac{\gamma}{q\left(\theta^{0}\right)}=\frac{x-w}{r+s}
$$

\footnotetext{
${ }^{11}$ In Section 5.1, we show that this condition is relaxed in the presence of bubbles.
} 
where $\theta^{0}$ is the fundamental value of labor market tightness. Bubbles are ruled out in Equation (4). Firm value is equal to the present discounted value of future profits, where the discount rate accounts for the probability of separations $s$.

\subsection{Stochastic bubbles in firm value}

We introduce bubbles that switch stochastically between latent and bubbly states. ${ }^{12}$

\subsubsection{Bubbles}

We restrict attention to positive bubbles in firm value. ${ }^{13} \mathrm{~A}$ bubble is always present in the model, but stochastically shifts between latent and bubbly states. Such transitions are modeled as exogenous shifts to the beliefs of some agents, and can be interpreted as changes in investor sentiment (Baker and Wurgler, 2006). Bubbly states are characterized by expectations of a divergent (growing) firm value by a positive mass of agents who believe in future capital gains and do not consider that a liquidity constraint will bind in finite time. Further, no other agent can engage in short selling. In contrast, latent states are characterized either by stationary expectations of all agents, or by the fact that agents not believing in a growing firm value can engage in short-selling without credit constraint.

The instantaneous probability that a bubbly state arises from a latent state is $\Upsilon \geq 0$. It can be interpreted as the probability that a positive mass of financially unconstrained agents start to believe that time derivatives in Equations (2) and (3) are different from zero. Therefore, these investors expect growth in firm value, even in the absence of expected growth in profits.

Bubbly states are assumed to end stochastically, either when the mass of agents believing in the bubble vanishes, that is, when they stop expecting an ever-growing firm

\footnotetext{
${ }^{12} \mathrm{~A}$ number of extensions and alternative specifications are is appendices. Appendix $\mathrm{C}$ shows that bubbles are solutions to the standard discrete-time recursive equation for firm value. Two alternative models of bubbles are described in Appendix D.

${ }^{13}$ We exclude price-decreasing bubbles, based on the idea that stocks are disposable assets. Negative bubbles would imply that the stock price would eventually become negative.
} 
value or when a mass of agents short sells without facing a liquidity constraint. The instantaneous probability that divergent expectations come to an end, conditional on being in the bubbly state, is $\Xi \geq 0$. For convenience, we sometimes refer to such events as the "burst" of the bubble, even though the bubble is still present afterwards, in its latent, non-explosive form. ${ }^{14}$

\subsubsection{Asset equations}

Hereafter, variables in the fundamental state (in which bubbles cannot arise), which we treat as our benchmark, are denoted using a superscript 0 . We denote variables in the bubbly state by a superscript $B$, and in the latent state (in which divergent expectations do not exist but may arise) with superscript $L$. In the bubbly state, asset values depend on the time elapsed since divergent expectations have started. We refer to this amount of time as the duration of the bubbly episode, and denote it by $\tau$. Hence, $J^{B}(0)$ denotes firm value at the start of a bubbly episode $(\tau=0)$. A summary of notation is in Appendix Table 6 .

The asset values for filled and unfilled vacancies are respectively, in the latent and bubbly states,

$$
\begin{gathered}
r J^{L}=x-w+s\left(J_{v}^{L}-J^{L}\right)+\Upsilon\left(J^{B}(0)-J^{L}\right)+\frac{\partial J^{L}}{\partial t} \\
r J^{B}(\tau)=x-w+s\left(J_{v}^{B}-J^{B}(\tau)\right)+\Xi\left(J^{L}-J^{B}(\tau)\right)+\frac{\partial J^{B}}{\partial t} \\
r J_{v}^{L}=-\gamma+q(\theta)\left(J^{L}-J_{v}^{L}\right)+\Upsilon\left(J_{v}^{B}(0)-J_{v}^{L}\right)+\frac{\partial J_{v}^{L}}{\partial t} \\
r J_{v}^{B}(\tau)=-\gamma+q(\theta)\left(J^{B}-J_{v}^{B}(\tau)\right)+\Xi\left(J_{v}^{L}-J_{v}^{B}(\tau)\right)+\frac{\partial J_{v}^{B}(\tau)}{\partial t}
\end{gathered}
$$

We maintain the assumption of a free-entry for vacancies, so that $J_{v}^{L}=0$ and $J_{v}^{B}(\tau)=0$ for any $\tau$. It follows that $\partial J_{v}^{L} / \partial t=0$ and $\partial J_{v}^{B}(\tau) / \partial t=0$. We acknowledge, however, that

\footnotetext{
${ }^{14} \mathrm{~A}$ mnemonic to remember notation associated with these Poisson rates is as follows: $\Xi(x i)$ resembles the superposition of letters $E$ and $X$ (as in "explosion"), while $\Upsilon$ (upsilon) looks like the opening of a bottle of champagne and its bubbles; or, alternatively, the fireworks of an "irrational exuberance" era.
} 
the free-entry assumption may be more difficult to maintain throughout a long period of bubble expansion.

To expose the main point and derive the mechanics of the transition from latent to bubbly states, we do not need to specify the exact wage determination process. Below, we derive solutions for several wage determination runs.

\subsubsection{Firm value in the latent state}

Denote $w^{L}$ the wage in the latent state. A steady-state equilibrium in the latent state implies that $\partial J^{L} / \partial t=0$. The equilibrium job creation condition, obtained from Equation (5), writes as

$$
J^{L}=\frac{x-w^{L}+\Upsilon J^{B}(0)}{r+s+\Upsilon}=\frac{\gamma}{q\left(\theta^{L}\right)},
$$

where $\theta^{L}$ is the steady-state labor market tightness in the latent state. Equation (9) states that the present discounted value of a vacancy in the latent state equals the present value of future profits, plus the present value of capital gains due to future bubbles, which may start with probability $\Upsilon$. Future flows are discounted to account for the fact that both separation and the appearance of bubbly episodes are stochastic events.

The latent state is characterized by a value of filled vacancies which is strictly higher than in the fundamental state, since $\theta^{L}>\theta^{0}$ whenever $\Upsilon>0$. Indeed, the value of a vacancy incorporates expectations over capital gains due to future bubbles. Hence, the latent state differs from the fundamental state of the economy. This difference highlights the fact that a bubble is always present, even though it is "latent" in this case, due to stationary expectations. Below, the difference between latent and fundamental states is characterized in greater details.

\subsubsection{Firm value in the bubbly state}

Denote $w^{B}$ the wage in the latent state. We make no assumption on its exact value, except that it is fixed between two aggregate states, whether the firm was created in the latent state (in which case the wage can possibly be renegociated when a bubbly episode starts) or in the bubbly state (in which case the wage of new hires can depend on the 
duration of the bubbly state but remains constant after job creation). Hence, the asset value of a filled job in the bubbly state (Equation 6) rewrites as a differential equation,

$$
(r+s+\Xi) J^{B}(\tau)=x-w^{B}+\Xi J^{L}+\frac{\partial J^{B}(\tau)}{\partial t}
$$

Solving for (10), the job creation condition in the bubbly state satisfies

$$
J^{B}(\tau)=\frac{x-w^{B}+\Xi J^{L}}{r+s+\Xi}+K e^{R \tau}
$$

where we denote by

$$
R=r+s+\Xi
$$

the growth rate of the bubble. This growth rate of the value of the asset is the sum of the risk-free-rate and the destruction of the bubbly asset, consistent with Tirole (1982, 1985) and Blanchard and Watson (1982).

The first term in Equation (11) is the present discounted value of future profits, plus that of future capital losses arising from the stochastic end of the bubbly episode. The second term is the value of the bubble $\tau$ periods after it started. $K$ is a constant of integration. It is indeterminate but can be interpreted as capturing the magnitude of the initial jump in firm value, as we show now.

\subsubsection{Jumps in firm value across states and interpretation of $K$}

The appearance of bubbly episodes is characterized by a jump in firm value, followed by an exponential increase until the bubble bursts. To characterize this dynamics, denote

$$
\Delta(\tau)=J^{B}(\tau)-J^{L}
$$

the capital gain from a bubble of duration $\tau$, relative to the latent state. Using the definition of the fundamental firm value $J^{0}$ (Equation 4 ), one has

$$
J^{L}=J^{0}+\frac{\Upsilon}{r+s} \Delta(0)
$$


Relative to the fundamental value, the value of a filled vacancy in the latent state is distorted upward, since the possibility that bubbles start, with probability $\Upsilon$, is priced. Moreover, the value of a filled position in the bubbly state is

$$
J^{B}(\tau)=J^{0}+\frac{R}{r+s} K e^{R \tau}-\frac{\Xi}{r+s} \Delta(\tau)
$$

which equals its fundamental value $J^{0}$, plus the capitalized value of the bubble after $\tau$ periods, net of the present value of future capital losses due to the burst of the bubble.

The values of the capital gains from the bubble, $\Delta(\tau)$, and that of the initial jump, $\Delta(0)$, can be derived in closed-form. Replacing (14) and (15) into (13) yields the value of $\Delta(\tau)$

$$
\Delta(\tau)=\frac{R}{r+s} K e^{R \tau}-\frac{\Xi}{r+s} \Delta(\tau)-\frac{\Upsilon}{r+s} \Delta(0)
$$

After some calculations (see Appendix B.1), the value of $\Delta(0)$ follows,

$$
\Delta(0)=K \frac{R}{R+\Upsilon}
$$

Therefore, the jump in firm value at the inception of the bubble is proportional to the constant of integration $K$ divided by the sum of all relevant discount factors. Furthermore,

$$
\Delta(\tau)-\Delta(0)=K\left[e^{R \tau}-1\right]
$$

that is, firm value grows exponentially after the emergence of a bubble. Together, (17) and (18) are central equations describing the dynamics of bubbles in firm value.

These equations make it possible to answer two questions regarding the integration constant $K$ and its interpretation. First, a question is whether $K$ can be pinned down under the assumption of continuity in firm value. Equations (18) shows that it is not possible. Indeed, solving for $J^{B}(0)=J^{L}$ yields $K=0$. Imposing continuity of the of the firm value function rules out bubbles. Instead, the appearance of a bubble needs to be associated with a jump in firm value that $K$ characterizes fully. Therefore, we treat $K$ as a parameter. Our restriction to positive bubbles implies $K>0$. 
A second question pertains to the interpretation of $K$, which is party behavioral. It can be interpreted as presbyopia (difficulty to see too small objects), rather than myopia about the future, in the following sense. When agents see changes in asset prices below some detection threshold, they do not infer that sustainable growth in asset prices will follow. In contrast, when they see a positive change in prices above the detection threshold (e.g., $2 \%$ in our calibration), they coordinate on the positive value of $K$. In that sense, the value of $K$ can be interpreted as the smallest possible fluctuation in asset prices above which some agents coordinate on the bubbly path.

\subsubsection{Labor market tightness across states}

In the bubbly state, by Equation (8), the value of a filled job satisfies

$$
J^{B}(\tau)=\frac{\gamma}{q\left(\theta_{\tau}^{B}\right)} .
$$

Since the same job creation condition prevails in the latent state (Equation 9), the inception of a bubble is therefore associated with a jump in labor market tightness. In the latent state, the value of labor market tightness is constant, even immediately after a bubble bursts from a higher value. This is the case since this equation always hold. Tightness immediately converge to the final steady-state, while vacancies and unemployment slowly converge. This process is described at a greater length in Sections 6.3.1 and 6.3.2.

We now describe the evolution of labor market tightness in the bubbly and latent states. Using the entry equations, Equations (18) and (17) further lead to

$$
\begin{aligned}
& \frac{\gamma}{q\left(\theta_{\tau}^{B}\right)}-\frac{\gamma}{q\left(\theta_{\tau=0}^{B}\right)}=K\left[e^{R \tau}-1\right], \\
& \frac{\gamma}{q\left(\theta_{\tau=0}^{B}\right)}-\frac{\gamma}{q\left(\theta^{L}\right)}=K \frac{R}{R+\Upsilon},
\end{aligned}
$$

which fully describe the dynamics of labor market tightness after a bubbly episode starts.

Before that, it is characterized by its stationary value. Using Equation (14) and replacing 
$J^{0}$ by its value yields

$$
\frac{\gamma}{q\left(\theta^{L}\right)}=\frac{\gamma}{q\left(\theta^{0}\right)}+\frac{\Upsilon}{r+s} \frac{R}{R+\Upsilon} K
$$

where $\theta^{0}$ is the fundamental value of labor market tightness. Tightness in the latent state is higher than in the fundamental state, by a term increasing in $K$. Intuitively, firms post more vacancies in the latent state than in the fundamental state, with the aim of already be operating and enjoy capital gains when a bubble emerges.

After the bubble starts, Equation (21) characterizes the jump of market tightness to its new value. Combined with Equation (22), it leads to the characterization of market tightness for $\tau=0$,

$$
\frac{\gamma}{q\left(\theta_{\tau=0}^{B}\right)}=\frac{\gamma}{q\left(\theta^{0}\right)}+\left(1+\frac{\Upsilon}{r+s}\right) \frac{R}{R+\Upsilon} K
$$

After this jump, Equation (20) shows the exponential increase of labor market tightness for any duration $\tau$ of the ongoing bubble. Replacing and simplifying yields

$$
\frac{\gamma}{q\left(\theta_{\tau}^{B}\right)}=\frac{\gamma}{q\left(\theta^{0}\right)}+K\left[e^{R \tau}+\frac{\Xi \Upsilon}{(R+\Upsilon)(r+s)}\right]
$$

Bubbles distort the fundamental allocation by increasing the tightness of the labor market. As workers and firms are matched at a higher rate, this induces unemployment to decrease.

\section{Wages}

We now endogenize wages by treating them as the endogenous outcome of a Nash bargaining process. We start by writing, in both states, the asset values of employment $\left(W^{L}\right.$ and $\left.W^{B}\right)$ and unemployment $\left(W_{u}^{L}\right.$ and $\left.W_{u}^{B}\right)$. Wages can potentially be affected by three events: i) the appearance of bubbles; ii) their disappearance; and iii) their expansion. We start by working under the assumption that wages are bargained at the time of job creation and constant afterwards. We also solve the model with fully flexible wages. 


\subsection{Worker value function}

Unemployed workers enjoy a per-period benefit $z$. We have

$$
\begin{gathered}
r W^{L}=w^{L}+s\left(W_{u}^{L}-W^{L}\right)+\Upsilon\left(W^{B}-W^{L}\right)+\frac{\partial W^{L}}{\partial t} \\
r W_{u}^{L}=z+\theta q(\theta)\left(W^{L}-W_{u}^{L}\right)+\Upsilon\left(W_{u}^{B}-W_{u}^{L}\right)+\frac{\partial W_{u}}{\partial t} \\
r W^{B}=w^{B}+s\left(W_{u}^{B}-W^{B}\right)+\Xi\left(W^{L}-W^{B}\right)+\frac{\partial W^{B}}{\partial t} \\
r W_{u}^{B}=z+\theta q(\theta)\left(W^{B}-W_{u}^{B}\right)+\Xi\left(W_{u}^{L}-W_{u}^{B}\right)+\frac{\partial W_{u}^{B}}{\partial t} .
\end{gathered}
$$

In contrast with asset equations for firm value, bubbles can be ruled out in asset equations for workers. Indeed, bubbles in firm value can exist because a firm's stock can be bought and sold in a liquid market, implying that a price above the fundamentals can be sustained under the expectation that the resale value of existing stocks will continue to grow. In contrast, there is no such liquid market for labor and human capital. This restricts the set of equilibria we study.

\subsection{Endogenous semi-flexible wages}

Our preferred specification is one in which wages are bargained at the time of job creation, but constant afterwards, until the aggregate state (latent or bubbly) changes, in which case the wage is renegotiated given the current value of the labor market tightness. We call such wages endogenous semi-flexible wages. We study the full-flexible case later on, which is shown to lead to another type of solution for firm's value which is not exponential, hence less relevant in our context.

First, in the latent state, we restrict to equilibria where wages and value functions are constant, $\partial W_{u}^{L} / \partial t=0$ and $\partial W^{L} / \partial t=0$. When bargaining occurs, the surplus of a match is assumed to be shared according to the Nash rule. We denote $\alpha>0$ the bargaining power of workers. 
The wage $w^{L}$ is time-independent and solves

$$
w^{L}=\operatorname{argmax}\left(W^{L}(w)-W_{u}^{L}\right)^{\alpha}\left(J^{L}(w)-J_{v}^{L}\right)^{1-\alpha}
$$

yielding a surplus-sharing rule

$$
(1-\alpha)\left(W^{L}-W_{u}^{L}\right)=\alpha J^{L}
$$

In the latent state, replacing value functions and solving for $w^{L}$ yields

$$
w^{L}=(1-\alpha) z+\alpha\left(x+\theta^{L} \gamma\right)
$$

See Appendix B.2 for the proof.

In the bubbly state, as the bubble grows, labor market tightness increases over time, which may be reflected in the solution to the bargaining problem at the time of job creation. However, after job creation, wages are not renegotiated, and firm value continues to grow while its fundamental value remains constant.

Denote by $\tau^{\prime} \geq \tau$ the time at which the different quantities are evaluated, where $\tau$ is the time elapsed since the start of a bubbly state. The solution for wages maintains the asset value of a job as a linear combination of a constant (in $\tau$ ) and of a term growing as exponential of $R \tau^{\prime}$. Denote by $J^{B}\left(0, \tau^{\prime}\right)$ the value of a job created at the time when the bubbly state emerged and evaluated after $\tau^{\prime}$ periods, and $w^{B}\left(0, \tau^{\prime}\right)$ the wage of a job re-negotiated at the time the bubbly state started and considered after $\tau^{\prime}$ periods. We have

$$
w^{B}(0,0)=(1-\alpha) z+\alpha\left(x+\theta_{\tau=0}^{B} \gamma\right)
$$

We prove in Appendix B.3 that if $w^{B}\left(0, \tau^{\prime}\right)$ is allowed to evolve over time, firm value would no longer be a combination of a constant and of an exponential term. Therefore, since we restrict attention to these solutions, a simpler notation for wages can be used. 
Hereafter, we denote by $w^{B}(0)=w^{B}(0,0)$ and

$$
w^{B}(\tau)=(1-\alpha) z+\alpha\left(x+\theta_{\tau}^{B} \gamma\right)
$$

the entry wage for a firm created during a bubbly episode with duration $\tau$.

It follows that the value of a firm created when a bubbly state emerges is

$$
J^{B}\left(0, \tau^{\prime}\right)=\frac{x-w^{B}(0)+\Xi J^{L}}{r+s+\Xi}+K e^{R \tau^{\prime}} .
$$

For a job created after the start of a bubbly state, when $\tau>0$, the value of a new firm has a similar form. However, since the current value of $\theta_{\tau}^{B}$ is higher, the wage negotiated at the time of job creation reflects these better conditions (for workers). Therefore, the value of a new job created $\tau$ periods after the bubbly state started and considered in $\tau^{\prime}>\tau$, is:

$$
J^{B}\left(\tau, \tau^{\prime}\right)=\frac{x-w^{B}(\tau)+\Xi J^{L}}{R}+K e^{R \tau^{\prime}} .
$$

Since $w^{B}(\tau)$ is increasing in $\tau$, the fundamental value of new jobs created as the bubble expands declines over time.

\subsection{Equilibrium with endogenous semi-flexible wages}

The equilibrium job creation condition is obtained by substituting the wage rule in the job creation condition. In the latent state, using the jump function $\Delta(0)$ and rearranging yields

$$
\frac{\gamma}{q\left(\theta^{L}\right)}=\frac{(1-\alpha)(x-z)-\alpha \theta^{L} \gamma}{r+s}+\frac{\Upsilon}{r+s} \Delta(0) .
$$

As compared with the standard Pissarides entry equation, the existence of expectations over future bubbles and associated capital gains $\Delta(0)$ leads to a higher number of vacancies being posted, thus to higher equilibrium tightness $\theta^{L}>\theta^{0}$.

In the bubbly state, at the time of job creation $\tau$, substituting the wage within the 
job creation condition yields, after some calculations,

$$
\frac{\gamma}{q\left(\theta_{\tau}^{B}\right)}=\frac{(x-z)(1-\alpha)-\alpha \gamma \theta_{\tau}^{B}}{r+s}+K\left(e^{R \tau}+\frac{\Xi}{r+s} \frac{\Upsilon}{R+\Upsilon}\right)
$$

See Appendix B.3 for the full derivation of the above two entry equations. Note also that the case where $K=0$ leads to the classical entry equations.

\subsection{Alternative: the fully-flexible wages case}

For completeness, we treat the case in which wages are fully flexible, and therefore renegotiated in continuous time. As discussed in Section 2, however, wages in U.S. data do not closely follow the dynamics of firm value during bubbly episodes. The solution nevertheless exhibits interesting features.

Under fully flexible wages, the differential equation solving for a firm's value is still given by

$$
R J^{B}(t)=x-w^{B}+\Xi J+\frac{\partial J^{B}(t)}{\partial t} .
$$

The derivation of the solution for fully flexible wages is in Appendix B.4. For a given

value of $\theta$, the wage has the same generic value as that in Equations (27), (28) and (29). However, the differential equation (33) is more complex to solve, since time-varying tightness enters. We have

$$
R J^{B}(t)=(x-z)(1-\alpha)-\theta_{t}^{B} \gamma+\Xi J^{L}+\frac{\partial J^{B}(t)}{\partial t}
$$

An explicit solution can be derived under the assumption that the matching function is Cobb-Douglas. Using the free-entry condition, tightness is linked to the market value of newly created firms by:

$$
\theta_{t}^{B}=\left(J^{B}(t) / \gamma\right)^{1 / \eta}
$$

where $\eta \in[0,1]$ is the elasticity of matching with respect to unemployment. Hence, firm 
value solves

$$
R J^{B}(t)=(x-z)(1-\alpha)+\Xi J^{L}-\gamma\left(J^{B}(t) / \gamma\right)^{1 / \eta}+\frac{\partial J^{B}(t)}{\partial t}
$$

There is no general solution to this equation. Particular solutions, however, exist when $1 / \eta$ is integer, for instance when $\eta=0.5$. In this case, the differential equation is known as

a Riccati equation. The new term $\gamma\left(J^{B}(t) / \gamma\right)^{1 / \eta}$ is a feedback mechanism that limits the expansion of the bubble due to the increase in wages. Deriving the solution for the firm value requires a few unreported steps. In short, it involves an intermediate function $f(t)$ which is the sum of two exponential terms weighted by two integration constants. One can be proved to be positive and the other to be negative. The solution is proportional to the ratio of the time derivative $f^{\prime}$ and of $f$ itself. Hence, in the general case, the limit of $J^{B}(t)$ when $t$ tends to infinity converges to a constant term. Furthermore, there is divergence in finite time if the two integration constant have opposite signs, otherwise the asset value remains bounded. For this reason, we exclude these solutions from our analysis of the bubbly state. Instead, from now on, we focus on the rigid endogenous wages discussed in Section 4.2. Particular solutions taking the form of Riccati equations will be studied in a separate paper.

\section{$5 \quad$ Entry and the (in-)efficiency of bubbles}

We study how the viability and efficiency of matching economies are affected by the presence of bubbles.

\subsection{Viability condition for a matching economy with bubbles}

The standard viability condition for a search-and-matching economy requires that the first vacancy created obtains a positive surplus, that is, $J>0$ when $\theta=0$. Under the Inada condition for the matching function, $\lim _{\theta \rightarrow+\infty} q(\theta)=+\infty$, the viability condition in the fundamental model is the first-best efficient inequality $x>z$. Market activity must 
be more productive than leisure.

In an economy with bubbles, Equation (31) in $\theta=0$ implies a milder condition in the latent state,

$$
(1-\alpha)(x-z)>-\Upsilon \Delta(0)
$$

This "apparent viability" condition may hold for $x<z$. This is because gains from trade are distorted in the presence of bubbles. Jobs can be created not because they are productive in real terms, but because of expected capital gains $\Delta(0)$ in the future.

In the bubbly state, from Equation (32), the viability condition is similar but, as the bubble expands, is even less and less restrictive on productivity relative to leisure. We have

$$
(1-\alpha)(x-z)>-K\left(e^{R \tau}(r+s)+\frac{\Upsilon \Xi}{R+\Upsilon}\right) .
$$

In other words, there are gains from trade arising purely from the existence of bubbles. Hiring decisions can eventually be made with little regard for the real productivity of jobs. This is the reason why many of these jobs are set to disappear when the bubble ends, even though this event is not associated with any change in labor productivity. Also note that when $K=0$, then $\Delta(0)=0$ and both viability conditions (36) and (37) collapse to $x=z$.

\subsection{Second-best efficiency}

The discussion on the "apparent" viability of a search economy can be generalized to second-best efficiency. When subject to the matching technology and choosing labor market tightness, the social planner aims to correct two distortions. First, there are standard congestion externalities arising from the search process. Second, there are distortions to fundamental allocations induced by bubbles. The comparison between the decentralized solution with endogenous wages and the social planner solution brings additional insights on the role of bubbles in a matching economy, and shows how bubble-induced distortions affect welfare. 


\subsubsection{Efficiency in the fundamental state}

In the fundamental economy, a second-best efficient equilibrium is reached when the workers' share of the total match surplus $\alpha$ is equal to the congestion externality coefficient $\eta_{q}(\theta) \in[0,1]$

$$
\alpha-\eta_{q}\left(\theta^{o p t}\right)=0
$$

as discussed in Hosios (1990) and Pissarides (2000). Here, $\eta_{q}(\theta)=-\theta q^{\prime}(\theta) / q(\theta)$ denotes

the elasticity of the job filling rate with respect to labor market tightness, and $\theta^{\text {opt }}$ is the socially optimal level of tightness. The social planner optimally sets a higher share of wages if unemployed workers create larger congestion on firms and reduce their hiring rate (large $\left.\eta_{q}\right)$.

\subsubsection{Efficiency in the latent and bubbly states}

To study welfare in the presence of bubbles, we state the social planner program as closely as possible to the standard second-best efficiency problem studied in Pissarides (2000). The social planner maximizes the present discounted value of output and leisure, net of search costs,

$$
\Omega=\int e^{-r t}(x(1-u)+z u-\gamma \theta u) \mathrm{d} t
$$

It chooses the level of tightness $\theta$, while being subject to the frictions imposed by the matching technology,

$$
\frac{\partial u}{\partial t}=s(1-u)-u f(\theta)
$$

The Hamiltonian associated with this problem writes as

$$
\mathcal{H}=e^{-r t}(x-z-\gamma \theta u)-\nu_{t}[s(1-u)-u f(\theta)]
$$

where $\nu_{t}$ is a co-state variable. Denoting $\dot{\nu}_{t}$ the time derivative of $\nu_{t}$ and deriving the optimality conditions yields

$$
-e^{-r t} \gamma+\nu_{t} \epsilon_{f}(\theta) q(\theta)=0
$$


and

$$
e^{-r t}[-x+z-\gamma \theta]+\nu_{t}(s+\theta q(\theta))=\dot{\nu_{t}},
$$

where $\epsilon_{f}(\theta)=-\theta f^{\prime}(\theta) / q(\theta)$ is the elasticity of the job finding rate with respect to labor market tightness, satisfying $1-\epsilon_{f}(\theta)=\eta_{q}(\theta)$. The social planner has no interest in bubbles, since its program is based on the fundamental values of utilities and profits.

Starting with the latent state, we obtain the usual efficient market-entry equation,

$$
\frac{\gamma}{q\left(\theta^{\text {opt }}\right)}=\frac{(x-z)\left(1-\eta_{q}\left(\theta^{o p t}\right)\right)-\gamma \theta^{o p t} \eta_{q}\left(\theta^{o p t}\right)}{r+s}
$$

Comparison of Equations (41) and (31) shows that the standard Hosios condition (38) is not valid. The social planner optimally sets a value of $\alpha$ higher than $\eta_{q}$ so that equilibrium market tightness is not too high in the decentralized equilibrium. More precisely, the socially efficient value of $\alpha$, denoted by $\alpha^{\prime}$, satisfies

$$
\alpha^{\prime}-\eta_{q}\left(\theta^{o p t}\right)=\frac{\Upsilon \Delta(0)}{x-z+\gamma \theta^{o p t}}
$$

It is straightforward to verify, given the value of $\Delta(0)$ in Equation (17), that the gap between $\alpha^{\prime}$ and $\eta_{q}$ is increasing in the three parameters related to the bubble $K, \Xi$ and $\Upsilon$. In the special case where bubbles are ruled out, $\Delta(0)=0$ leads back to the standard constrained efficiency condition. The interpretation is easy: private agents expect future bubbles to generate capital gains $\Delta(0)$, and therefore create more vacancies before the expansion of the bubble than they would do otherwise. Whether this improves or reduces efficiency depends on the relative values of $\alpha$ and $\eta_{q}\left(\theta^{\text {opt }}\right)$ is the fundamental case. If Equation (38) holds in the fundamental case, then bubbles decrease efficiency. Constrained efficiency can be restored by setting higher wages, thereby reducing incentives to create excess vacancies.

Turning to the bubbly state, and keeping the assumption that the social planner is unconstrained in its choice of $\theta$, beyond the matching constraint, the steady-state in Equations (39) and (40) is still constrained efficient. Therefore, the comparison of the 
social optimum (41) with the decentralized bubbly equilibrium at time $\tau=0$ in (32) leads the social planner to want an even larger bargaining parameter $\alpha^{B}$ which is now defined by

$$
\alpha^{B}(\tau)-\eta_{q}\left(\theta^{o p t}\right)=K \frac{e^{R \tau}(r+s)+\left(\frac{\Xi \Upsilon}{R+\Upsilon}\right)}{x-z+\gamma \theta^{o p t}} .
$$

Note that this modified Hosios rule is a temporary one, in the sense that it depends on $\tau$, the time elapsed since the start of the expansion period. Indeed, as the bubble expands, the decentralized equilibrium deviates further from the steady-state efficient labor market tightness and, accordingly, the social planner wants to tax firms by setting increasing values of $\alpha^{\prime B}$. However, after $\tau$ reaches a threshold, the value of $\alpha^{B}$ reaches one, in which case firms receive no profit from matches, and yet still create excess vacancies. The solution for the social planner is to set $\alpha^{\prime B}$ above one. This corresponds to an overlooked solution to the constrained-efficient solution in matching models, where bubbles are so distortive than the social planner wants to cool down the economy by imposing growing losses to firms until expectations of ever-growing capital gains vanish.

Note finally that, regardless of whether bubbles increase or reduce efficiency in the early phase of a bubble, it necessarily reduces efficiency when it lasts for too long. Even though bubbles reduce unemployment and increase gross output, they are not desirable from the social planner perspective, since they increase posting costs and congestion externalities too much.

To fix ideas, the magnitude of deviations from the Hosios rule is small initially but grows slowly. Using the parameter values of our baseline calibration, further discussed in Section 7.1, we show the following: in the latent state, the magnitude of deviations the Hosios rule (given by the right-hand side of Equation 42) equals 0.0002. At the start of a bubbly state, when $\tau=0$, the magnitude of the deviations (Equation 43) is 0.0012 . Therefore, at the inception of a bubble, correcting deviations induced by bubbles requires only small deviations, in the form of increases in wages. However, the magnitude of the optimal deviation $\alpha^{B}(\tau)-\eta_{q}\left(\theta^{\text {opt }}\right)$ increases exponentially over time. Therefore, the time needed for the optimal share of workers in match surplus, $\alpha^{\prime B}(\tau)$, to reach 1 can be computed. With our baseline calibration, it takes 27 quarters. These numbers give an 
indication of the magnitude of inefficiencies generated by the existence of bubbles. Even though distortions may be quantitatively small early in a bubble, they can become large if bubbles last just a few years.

\section{Aggregate shocks and short-term dynamics}

We introduce an aggregate process for labor productivity, needed to compare the model with the data. Since our focus is on the volatility of labor market outcomes, we also discuss the elasticity of labor market tightness to these shocks, and the short-run adjustment of unemployment and vacancies to both productivity shocks and bubbles.

\subsection{Extension to productivity shocks}

We assume that aggregate productivity $x$ varies stochastically, according to a Poisson process with intensity $\lambda$. The distribution of productivity is characterized by a c.d.f. $G_{x}(x)$ with support $\left[x_{\min }, x_{\max }\right]$. The subscript $x$ implies that the distribution is statedependent and only depends on current productivity, so as to allow for persistence in productivity innovations. We also postulate that $x_{m i n}$ satisfies Equation (36), i.e., is high enough to ensure that the firm is not destroyed in the latent state. We assume that the Poisson processes driving exogenous firm destruction, as well as the appearance and disappearance of bubbles, are independent of aggregate productivity.

The value of a filled vacancy in the latent state is

$$
(r+s+\Upsilon+\lambda) J^{L}(x)=x-w^{L}+\lambda \int_{x_{\min }}^{x_{\max }} J^{L}\left(x^{\prime}\right) \mathrm{d} G_{x}\left(x^{\prime}\right)+\Upsilon J^{B}(\tau=0, x) .
$$

In the bubbly state, the asset value of a filled vacancy writes as

$$
(R+\lambda) J^{B}(\tau, x)=x-w^{B}+\Xi J^{L}(x)+\lambda \int_{x_{\min }}^{x_{\max }} J^{B}\left(\tau, x^{\prime}\right) \mathrm{d} G_{x}\left(x^{\prime}\right)+\frac{\partial J^{B}}{\partial t},
$$

i.e., a partial differential equation for $J^{B}(\tau, x) .{ }^{15}$ We postulate the existence of solution

\footnotetext{
${ }^{15}$ We highlight a slight abuse of notation in Equation (45). We keep the partial derivative in time with
} 
of the form $a(x+b)+K e^{g \tau}$ where firm value grows exponentially at a constant rate $g$ between two productivity changes. It is easy to verify that $g=r+s+\Xi=R$, as before, and that $a=(r+s+\Xi)^{-1}$. Similarly, looking for linear solutions for $J^{L}(x)=a^{\prime}\left(x+b^{\prime}\right)$, one easily verifies that $a^{\prime}=(r+s+\Upsilon)$.

\subsection{Elasticities and volatility}

To assess the sources of volatility in the presence of stochastic productivity shocks, we calculate the elasticity of labor market tightness $\theta$ to $x$. Combining the above equations with free-entry yields an expression for labor market tightness in each state,

$$
R^{-1}(x+b)+K e^{R \tau}=\frac{\gamma}{q\left(\theta_{\tau}^{B}\right)}
$$

and

$$
a^{\prime}\left(x+b^{\prime}\right)=\frac{\gamma}{q\left(\theta^{L}\right)} .
$$

Based on these expressions, the elasticity of labor market tightness to current productivity is easily derived. In the latent state,

$$
\frac{d \cdot \ln \left(\theta^{L}\right)}{d \cdot \ln (x)}=\eta_{q}^{-1} \frac{a^{\prime} x}{a^{\prime}\left(x+b^{\prime}\right)}
$$

where $\eta_{q}$ is the elasticity of $q($.$) , defined in Section 5.2. Therefore, at constant wages,$ the elasticity of $\theta$ to $x$ is close to its fundamental value, slightly below the inverse of $\eta_{q}$. Turning to the bubbly state,

$$
\frac{d \cdot \ln \left(\theta_{\tau}^{B}\right)}{d \cdot \ln (x)}=\eta_{q}^{-1} \frac{a x}{a(x+b)+K e^{R \tau}}
$$

Fluctuations in $\theta$ over time are driven by both productivity fluctuations and by transitions between latent and bubbly states. Equation (46) makes it apparent that, as the bubble expands, the volatility of the economy in response to productivity shocks tends respect to $t$, not $\tau$. This is to remind the reader that, formally, beside the growth of the bubble with $\tau$, other macroeconomic factor may affect the value of the bubble. 
asymptotically to zero (at a given $x$ ). An increasing part of fluctuations in labor market tightness is driven by the exponential increase in the value of the bubble. As we show below using simulations, this channel is key to generate higher volatility of market tightness. Additionally, another implication of Equation (46) is that the co-movement of labor market tightness with labor productivity is lower than in the fundamental model. This is because bubbles induces fluctuations in $\theta$ even when productivity remains constant.

\subsection{Short-run dynamics}

We discuss the short-run dynamics, in response to both productivity shocks and bubbles. We highlight that labor market tightness adjusts instantaneously to any change in conditions - either a change in productivity or the emergence of a bubble. This is because vacancies jump to their new optimal value, given by the free-entry condition. Instead, unemployment adjusts more slowly, at the speed of convergence given by transition rates $s$ and $f(\theta)$. Therefore, at each point in time $\tau$ within the bubbly regime, labor market tightness $\theta_{\tau}^{B}$ is at its equilibrium value, determined in Equation (32). Similarly, when a bubbly episode ends, vacancies jump to a lower value and $\theta$ reaches its steady-state equilibrium value (Equation 31).

\subsubsection{Dynamics following productivity changes}

The effect of a permanent change in productivity $x$ in the latent state is characterized in Panel A of Figure 4. We plot the Beveridge curve together with the equilibrium job creation condition. ${ }^{16}$ Starting from the equilibrium point A, a permanent increase in $x$ induces vacancies to jump to point $\mathrm{B}$. Then, unemployment converges to point $\mathrm{C}$, as matches are formed. During the adjustment, labor market tightness remains fixed, at a higher level than its initial level. Similarly, a permanent decrease in $x$, restoring the initial value of productivity, induces vacancies to jump down (to point D), and is followed by an increase in unemployment. This is similar to the counter-cyclical loops identified in Pissarides (1985). The dynamics following transitory changes in productivity is similar,

\footnotetext{
${ }^{16}$ The Beveridge curve is obtained by setting $\partial u / \partial t=0$ in Equation (1).
} 
with the difference that the convergence of the $(v, u)$ locus to its new steady state may not be complete, due to new shocks occurring during convergence.

\subsubsection{Dynamics during bubbles}

The short-run adjustment to a transition between the latent and the bubbly states is characterized in Panel B of Figure 4. The ergodic state in the latent state is given by the intersection of the Beveridge curve and of the latent job creation condition (point A). The appearance of a bubble leaves the Beveridge curve unchanged but rotates the value of equilibrium market tightness counterclockwise, since $\theta_{\tau=0}^{B}>\theta^{L}$. The adjustment of market tightness is instantaneous. In the short-run, $u$ remains unchanged, so the economy jumps to point B. If the bubble were not to grow, the $(v, u)$ locus would slowly converge to the intersection between the new job creation condition and the Beveridge curve. Instead, since the bubble expands, there are two joint and competing dynamics characterizing the $(v, u)$ locus. First, firm value $\gamma / q\left(\theta_{\tau}^{B}\right)$ grows at an exponential rate $R$. The increase in market tightness induces firms to post more and more vacancies. Second, there is also partial convergence to the Beveridge curve. The economy evolves along the dotted line that leads to point C. Convergence is never achieved when $\theta_{\tau}^{B}$ increases along with the bubble. When the bubble bursts (point $\mathrm{C}$ ), vacancies jump down, and unemployment then converges to its equilibrium latent value, characterized by a market

tightness $\theta^{L}$. The convergence of the $(v, u)$ locus to the Beveridge curve is achieved only in the latent state.

A novel feature of our model is that such countercyclical loops arise because of bubbles, and possibly in the absence of any productivity change. Furthermore, the quadrilateral is distorted by the race between the convergence of $u$ and the divergence of $\theta_{\tau}^{B}$.

\section{Quantitative properties}

We calibrate and simulate the model to study its quantitative properties. Our main result is that bubbles jointly generate a high volatility of both financial and labor market 


\section{Figure 4 - Dynamics of the economy with stochastic bubbles}

This figure illustrates dynamic labor market adjustments in the $(u, v)$ space. Panels $\mathrm{A}$ and B are respectively for the latent and bubbly states. In each panel, the blue line is the Beveridge curve and the pink lines are job creation conditions. In Panel A, we describe the adjustment to a permanent shift in productivity. An increase in productivity is associated with a jump in vacancies and in labor market tightness. As workers get matched to vacancies, the economy moves along the job creation condition line, and unemployment decreases. In Panel B, the productivity is unchanged, but the economy jumps to the bubbly state from $\mathrm{A}$ to $\mathrm{B}$, which evolves to $\mathrm{C}$ at the time where the bubble explodes and returns slowly to the latent steady state. See Section 6.3 for detailed explanations.

Panel A: Adjustment to a permanent productivity shock - Latent state

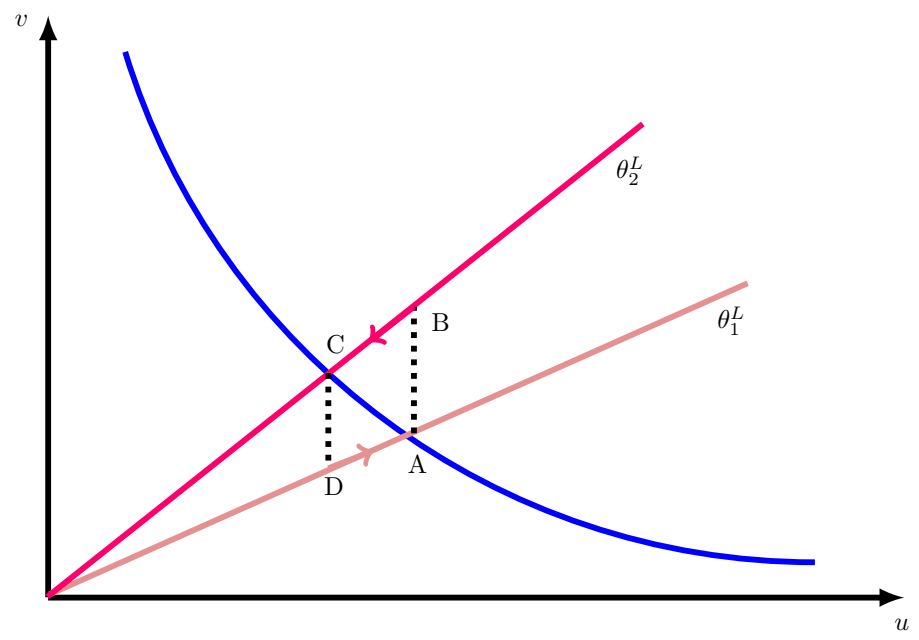

Panel B: Adjustment to the transition between latent and bubbly states

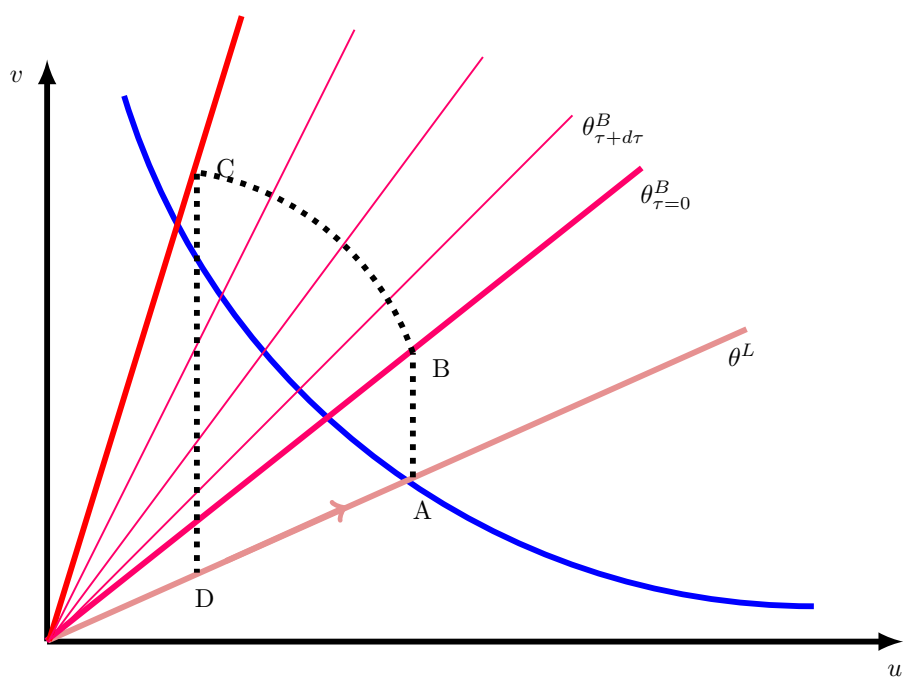

variables. 


\subsection{Calibration}

\subsubsection{Standard parameters}

For calibration and simulation, we transform the continuous-time model into its discretetime equivalent and normalize one time period as representing one quarter. At this frequency, five parameters are calibrated as in Shimer (2005). The quarterly discount rate is $r=0.012$. We set the separation rate $s$ to 0.1 , implying an average job duration of 2.5 years. We set the value of leisure $z$ to 0.4 , which can therefore be interpreted as unemployment benefits. The cost of posting a vacancy is set to $\gamma=0.213$. We also set workers' bargaining power to $\alpha=0.72$.

To specify the matching function, we depart from the Cobb-Douglas specification of Shimer (2005) and follow den Haan et al. (2000), by using $m(u, v)=v u /\left(v^{\nu}+u^{\nu}\right)^{1 / \nu}$. In a discrete-time calibration, this matching function has the appealing feature of being bounded between 0 and 1. During bubbles, since labor market tightness may rise well above its fundamental value, this feature is particularly relevant. Following den Haan et al. (2000), we calibrate $\nu=1.27$, which allows replicating empirical matching probabilities. With this matching function, the job filling rate is $q(\theta)=\left(1+\theta^{\nu}\right)^{-1 / \nu}$.

We model labor productivity as an $\mathrm{AR}(1)$ in logs,

$$
\log \left(x_{t}\right)=\rho \log \left(x_{t-1}\right)+\epsilon_{t}
$$

with $\rho \in[0,1]$ and $\epsilon_{t} \sim \mathcal{N}(0, \sigma)$. We transform it into a discrete-time Markov chain using Tauchen (1986)'s method, letting $\log \left(x_{t}\right)$ take 35 points of support in $\left[-5 \sigma / \sqrt{1-\rho^{2}}\right.$, $\left.+5 \sigma / \sqrt{1-\rho^{2}}\right]$. Parameters $\rho$ and $\sigma$ are calibrated so as to match the empirical standard deviation and autocorrelation of labor productivity (see Appendix A for details on data used). We obtain $\rho=0.92$ and $\sigma=0.011$. All calibrated parameter values are summarized in Table 2. 


\section{Table 2 - Calibrated parameter values}

We summarize the calibration of the model parameters. Labor market parameters are calibrated following Shimer (2005), with the exception of the matching function. Bubble parameters are calibrated based on financial data. The exogenous process for productivity is calibrated as an $\mathrm{AR}(1)$ to match the empirical volatility and autocorrelation of labor productivity in U.S. data, as collected in Panel A of Table 1.

\begin{tabular}{clcc}
\hline Parameter & Definition & Value & Source \\
\hline$s$ & Separation rate & 0.1 & Shimer (2005) \\
$r$ & Discount rate & 0.012 & Shimer (2005) \\
$z$ & Value of leisure & 0.4 & Shimer (2005) \\
$q(\theta)$ & Matching function & $\left(1+\theta^{1.27}\right)^{-1 / 1.27}$ & den Haan et al. (2000) \\
$\alpha$ & Bargaining power & 0.72 & Shimer (2005) \\
$\gamma$ & Cost of posting a vacancy & 0.213 & Shimer (2005) \\
$\Upsilon$ & Probability that a bubbly state starts & $1 / 32$ & Baker and Wurgler (2006) \\
$\Xi$ & Probability that a bubbly state ends & $1 / 8$ & Baker and Wurgler (2006) \\
$K$ & Initial value of bubble on firm value & $2 \% \cdot J^{0}$ & U.S. data \\
& & & See Equation (47) \\
$x$ & Productivity & Stochastic & U.S. data \\
$\sigma$ & Standard deviation of productivity & 0.011 & U.S. data \\
\hline & Autocorrelation of productivity & 0.92 & \\
\hline
\end{tabular}




\subsubsection{Parameters governing bubbles}

Compared to the fundamental model, there are three additional parameters to be calibrated: the frequencies at which bubbly expectations appear $(\Upsilon)$ and disappear $(\Xi)$, as well as the initial size of the jump in firm value $(K)$.

Our calibration strategy for these parameters targets financial moments, not the labor market moments in which we are ultimately interested. To calibrate $\Upsilon$ and $\Xi$, information on the frequency of occurrence of bubbles, as well as on their average duration, is needed. We follow the historical account of stock market bubbles by Baker and Wurgler (2006). They document four main bubbles over the 1961-2002 period: i) 1961 to 1962, ii) 1967 to 1968 , iii) late 1970s to 1983 , iv) 1999-2000. This account suggests that there is on average one bubbly episode every 10 years, and that a bubbly episode lasts on average 2 years. We take this approximation and consider that, within an average period of 10 years, the economy spends 2 years in the bubbly state and 8 years in the latent state. Consequently, we calibrate, at a quarterly frequency, $\Upsilon=1 / 32$ and $\Xi=1 / 8$. In our context, a calibration of the parameters governing bubbles based on Baker and Wurgler (2006) is well-suited, since their definition of bubbles is close to ours: the explain the aggregate behavior of the stock market by shifts in investor sentiment. Furthermore, their data covers a sample period which is almost similar to ours.

This approach to calibration has a number of shortcomings, however. First, the length of available stock market series is limited to a few decades, so the number of bubbly episodes to be used for calibration is small. Second, the classification of each stock market rise and fall as a bubble can be debated. For example, Pastor and Veronesi (2006) challenge the view that the rise and fall of technology stocks in the 1990s was a bubble. Similar discussions pertain to the duration of bubbles. As an example, Shiller (2015, Chapter 1) considers that bubbles last for longer periods of time, based on sustained increases in the $\mathrm{P} / \mathrm{E}$ ratio. Third, a last potential problem is that short-lived bubbles may not be detected, and therefore may not be part of available historical accounts. While these concerns do not systematically point to a bias of our parameterization in a unique direction, by either over- or under-emphasizing the prevalence of bubbles, we address 
them by exploring alternative calibrations in Section 7.3.

Finally, we calibrate $K$, which determines the size $\Delta(0)$ of a bubble at its inception and its height $\Delta(\tau)$ when it grows (Equations 17 and 16, respectively). Since the exact inception date of a bubble is not observed, $\Delta(0)$ is not observed. Calibrating $K$ based on $\Delta(\tau)$ raises a similar problem. We take an alternative approach and calibrate $K$ to match the empirical volatility of stock market value of firms (equal to 0.151, see Table 1). We obtain a value of $K$ that equals $2 \%$ of the fundamental firm value $J^{0}$.

\subsection{Baseline results}

First, we compare the moments of our model with stochastic bubbles with moments from the fundamental model, that is, the standard matching model without bubbles. To ensure comparability, we always use the same wage rule across comparisons, as calculated in Equations (27) and (28). In this section, we report results for which the wage is a weighted average of current productivity and the value of leisure, plus a term reflecting market tightness at the time of job creation. In case of a change between latent and bubbly states, the wage is also adjusted to current labor market tightness. It then remains constant afterwards with respect to tightness and only responds to productivity shocks.

For the simulation of each model, we let the economy start at its non-stochastic steady state, simulate 300 periods of data, and drop the first 50 periods. The resulting sample contains 250 periods of simulated data (62.5 years), and therefore closely resembles our U.S. data series, which last for 252 quarters (63 years). 1,000 such samples are simulated. Standard deviations for the moments of interest are computed across these simulated samples. As an illustration, Figure 5 plots 50 years of simulated data both for the fundamental model and for the model with bubbles.

Simulated moments are collected in Table 3. All of them are computed using log deviations from an HP trend with smoothing parameter 100,000. Our focus is on the volatility of labor market variables. In this respect, the model provides significant quantitative improvement. The volatility of labor market tightness $\theta$ is 9 times higher than in the standard model with no bubbles and a similar wage rule (0.232 instead of 0.026$)$. The 
volatility of the job finding rate is 6 times higher than in the fundamental model $(0.082$ vs. 0.014). Both are reasonably close to the data (0.371 and 0.136 , respectively), even though they are slightly lower. The volatility of vacancies (equal to 0.179 ) is also close to that observed in the data (0.187), and much higher than that generated by the standard model (0.018). Finally, even though unemployment in our model is six times more volatile than in the standard model (0.069 vs. 0.011), it remains less volatile than vacancies. In contrast, both have similar volatilities in the data. As Shimer (2005) highlights, this is due to a feature of the standard model which our model keeps, namely that unemployment adjusts slowly following a shock, while vacancies immediately jump to their new equilibrium value determined by free-entry. Additional features by which vacancies would become a state variable, such as adjustment costs, would induce the volatilities of unemployment and vacancies to be more in line with each other.

We highlight that the additional volatility generated by bubbles truly reflects changes in quantities of labor demanded by firms due to changes in expectations and not hidden wage stickiness. Indeed, given the wage rule retained here, the model with bubble embeds additional responsiveness to labor market conditions since wages adjusts upward and downward to changes in labor market tightness during transitions between the latent and the bubbly state. By construction, this feature does not exist in the fundamental model. Due to this channel, wages are more flexible in the model with bubbles, which plays against us finding additional volatility. Indeed, it is well-known, at least since Shimer (2005), that less wage flexibility is needed to generate higher volatility.

Next, we report matrices of correlation between all main variables (Table 3). It is noticeable that the introduction of bubbles breaks the near-perfect correlation between productivity shocks and labor market tightness that characterizes the standard model a feature that was most criticized. Instead, bubbles induce an autonomous dynamics of labor market tightness due to expectations of growth in firm value. Productivity is no longer the only variable that moves incentives to post vacancies. From the social planner's perspective, however, a low correlation between labor market variables and productivity highlights that deviations from the constrained efficient allocation (see Section 5.2.2) 
are potentially large. Indeed, it means that a sizable part of the observable labor market dynamics does not contribute to increasing the fundamental values of utilities and profits.

Finally, we stress that the model fails to deliver a high enough persistence (i.e., autocorrelation of growth rates) of the main labor market variables. This is also a shortcoming of the standard model. Again, this is a consequence of the fact that vacancies immediately jump to their new equilibrium value after a shock. Unemployment, which is a state variable, is the only variable with positive and significant persistence, yet lower than in the data (0.286, as compared to 0.588 in the data and to 0.271 in the fundamental model). In our model, expansion during a bubbly episode generates additional persistence. However, the burst of the bubble is associated with an extremely quick drop in vacancies and market tightness. Together, these two forces are not sufficient to generate higher persistence. In our concluding remarks (Section 8), we suggest a few possible extensions that could improve the quantitative fit of the model over this dimension. 
Table 3 - Simulated moments - Fundamental model vs. model with bubbles

This table contains our baseline simulation results. The wage is computed based on the labor market tightness at the time of job creation and updated with productivity shocks. Moments for all variables are computed using log deviations from an HP trend with smoothing parameter 100,000. Calibrated parameter values are summarized in Table 2. Bootstrapped standard errors are in parentheses. Standard errors are computed using 1,000 model solutions for 250 quarters. Persistence refers to the autocorrelation of the first differences for each variable.

\begin{tabular}{|c|c|c|c|c|c|c|c|c|}
\hline & & \multicolumn{5}{|c|}{ Labor market moments } & \multicolumn{2}{|c|}{ Financial moments } \\
\hline & & $u$ & $v$ & $\theta$ & $f$ & $x$ & $J$ & $J /(x-w)$ \\
\hline \multicolumn{9}{|c|}{ Fundamental model (wages depend on current productivity and entry $\theta$ ) } \\
\hline St. dev. & & $\begin{array}{c}0.011 \\
(0.001)\end{array}$ & $\begin{array}{c}0.018 \\
(0.001)\end{array}$ & $\begin{array}{c}0.026 \\
(0.002)\end{array}$ & $\begin{array}{c}0.014 \\
(0.001)\end{array}$ & $\begin{array}{c}0.020 \\
(0.001)\end{array}$ & $\begin{array}{c}0.011 \\
(0.001)\end{array}$ & $\begin{array}{c}0.027 \\
(0.003)\end{array}$ \\
\hline Autocorr. & & $\begin{array}{c}0.921 \\
(0.010)\end{array}$ & $\begin{array}{c}0.607 \\
(0.036)\end{array}$ & $\begin{array}{c}0.837 \\
(0.021)\end{array}$ & $\begin{array}{c}0.837 \\
(0.021)\end{array}$ & $\begin{array}{c}0.848 \\
(0.020)\end{array}$ & $\begin{array}{c}0.837 \\
(0.021)\end{array}$ & $\begin{array}{c}0.959 \\
(0.009)\end{array}$ \\
\hline Persistence & & $\begin{array}{c}0.271 \\
(0.034)\end{array}$ & $\begin{array}{l}-0.280 \\
(0.030)\end{array}$ & $\begin{array}{l}-0.083 \\
(0.035)\end{array}$ & $\begin{array}{l}-0.083 \\
(0.035)\end{array}$ & $\begin{array}{l}-0.046 \\
(0.035)\end{array}$ & $\begin{array}{l}-0.083 \\
(0.035)\end{array}$ & $\begin{array}{c}0.147 \\
(0.044)\end{array}$ \\
\hline & $u$ & 1 & -0.557 & -0.819 & -0.819 & -0.825 & -0.819 & 0.306 \\
\hline & $v$ & - & 1 & 0.933 & 0.933 & 0.920 & 0.932 & -0.057 \\
\hline Correlation & $\theta$ & - & - & 1 & 0.999 & 0.993 & 0.999 & -0.172 \\
\hline matrix & $f$ & - & - & - & 1 & 0.993 & 0.999 & -0.172 \\
\hline & $x$ & - & - & - & - & 1 & 0.994 & -0.177 \\
\hline & $J$ & - & - & - & - & - & 1 & -0.172 \\
\hline & $J /(x-w)$ & - & - & - & - & - & - & 1 \\
\hline \multicolumn{9}{|c|}{ Model with bubbles (wages depend on current productivity and entry $\theta$ ) } \\
\hline St. dev. & & $\begin{array}{c}0.069 \\
(0.014)\end{array}$ & $\begin{array}{c}0.179 \\
(0.045)\end{array}$ & $\begin{array}{c}0.232 \\
(0.059)\end{array}$ & $\begin{array}{c}0.082 \\
(0.016)\end{array}$ & $\begin{array}{c}0.020 \\
(0.001)\end{array}$ & $\begin{array}{c}0.153 \\
(0.042)\end{array}$ & $\begin{array}{c}0.356 \\
(0.101)\end{array}$ \\
\hline Autocorr. & & $\begin{array}{c}0.912 \\
(0.012)\end{array}$ & $\begin{array}{c}0.666 \\
(0.040)\end{array}$ & $\begin{array}{c}0.811 \\
(0.017)\end{array}$ & $\begin{array}{c}0.841 \\
(0.021)\end{array}$ & $\begin{array}{c}0.848 \\
(0.020)\end{array}$ & $\begin{array}{c}0.793 \\
(0.017)\end{array}$ & $\begin{array}{c}0.929 \\
(0.027)\end{array}$ \\
\hline Persistence & & $\begin{array}{c}0.286 \\
(0.015)\end{array}$ & $\begin{array}{l}-0.212 \\
(0.017)\end{array}$ & $\begin{array}{l}-0.050 \\
(0.010)\end{array}$ & $\begin{array}{l}-0.025 \\
(0.016)\end{array}$ & $\begin{array}{l}-0.047 \\
(0.035)\end{array}$ & $\begin{array}{l}-0.059 \\
(0.010)\end{array}$ & $\begin{array}{c}0.352 \\
(0.149)\end{array}$ \\
\hline \multirow{7}{*}{$\begin{array}{l}\text { Correlation } \\
\text { matrix }\end{array}$} & $u$ & 1 & -0.690 & -0.828 & -0.822 & -0.118 & -0.811 & 0.287 \\
\hline & $v$ & - & 1 & 0.977 & 0.940 & 0.083 & 0.973 & 0.013 \\
\hline & $\theta$ & - & - & 1 & 0.969 & 0.099 & 0.992 & 0.098 \\
\hline & $f$ & - & - & - & 1 & 0.154 & 0.927 & 0.017 \\
\hline & $x$ & - & - & - & - & 1 & 0.068 & 0.012 \\
\hline & $J$ & - & - & - & - & - & 1 & 0.011 \\
\hline & $J /(x-w)$ & - & - & - & - & - & - & 1 \\
\hline
\end{tabular}




\section{Figure 5 - Simulated time series data}

This figure plots one simulation of the model over a period of 50 years (200 quarters). In each chart, the blue line corresponds to the fundamental model and the the red line to the model with bubbles. Both are simulated using the baseline calibration of Table 2. The same path of productivity shocks is used to simulate both models. We report the simulated time series data of productivity $(x)$, firm value $(J)$, labor market tightness $(\theta)$ and employment $(n)$.

\section{Productivity $(x)$}

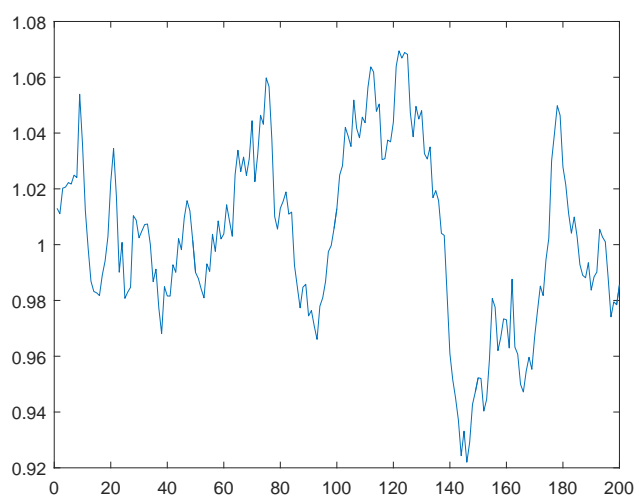

Labor market tightness $(\theta)$

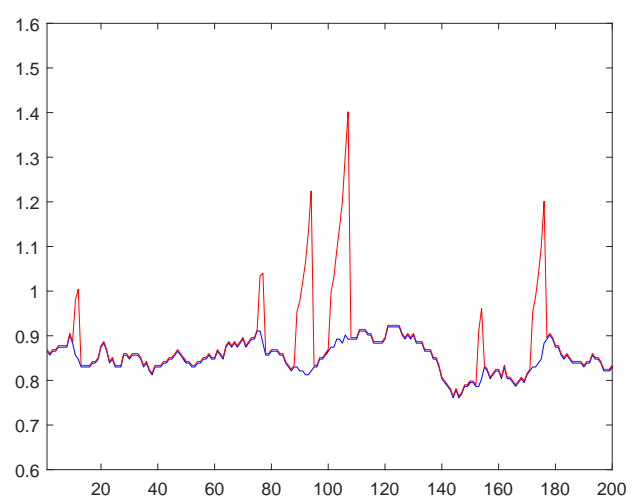

Firm value $(J)$

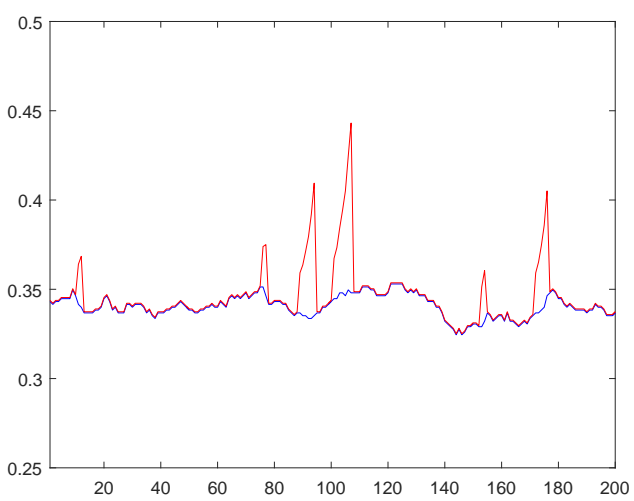

Employment $(n)$

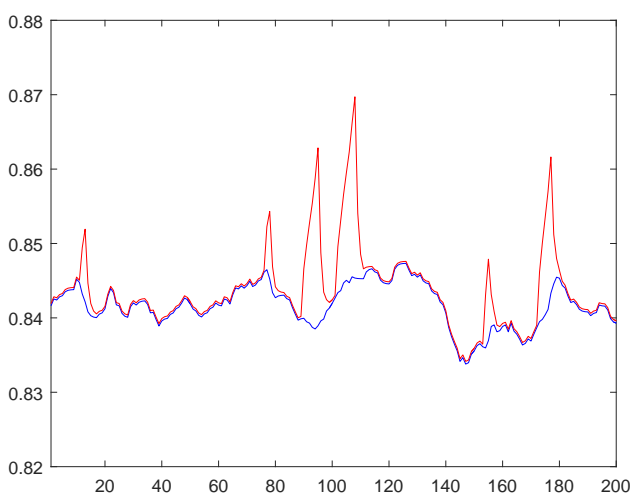




\subsection{Alternative parameterizations}

Finally, we explore how alternative specifications and parameter values affect the simulated moments.

As a first exercise, we adopt an alternative wage rule. The wage depends on the level of productivity at the time of job creation and remains constant afterwards. Therefore, wages are less flexible than in our baseline case. As is well-known, this generates higher volatility in the standard model. In Table 4, we show that this alternative wage rule indeed augments the volatility of labor market tightness by a significant factor. It now reaches 0.124 in the fundamental model, i.e., a third of the value observed in the data. In the model with bubbles, the same wage rule generates a volatility of labor market tightness which is twice higher, equal to 0.262 . It is therefore even closer to the data. From this exercise, we again see that the model with bubbles does not rely on wage rigidity to generate higher volatility. Instead, the autonomous dynamics of job creation through expectations is sufficient to create large volatility.

Next, to conclude this section, we revert back to the benchmark wage rule, and explore the sensitivity of the simulated moments to the three parameters capturing the occurrence and magnitude of bubbles, $\Upsilon, \Xi$ and $K$. We vary one parameter at a time, while keeping all other parameters at their baseline value. In Table 5, we report simulated volatilities with the baseline and with six alternative calibrations.

The main takeaway is that simulated volatilities are not overly sensitive to the choice of the parameters governing bubbles. In particular, the introduction of bubbles provides significant quantitative improvement to the standard model even if bubbles have a low probability of appearing, a low average duration, or are associated with small initial jumps in firm value. Therefore, the ability of a model with bubbles to generate higher volatility is not due to the specifics of our baseline calibration. For example, reducing $\Upsilon$ from $1 / 32$ to $1 / 40$ (i.e., a bubble starts after 10 years in the latent state on average) generates standard deviations of $\theta$ and $f$ of 0.210 and 0.063 (as compared to 0.026 and 0.014 in the fundamental model, and 0.371 and 0.136 in the data), respectively. Similarly, even with an average duration of one years $(\Xi=1 / 4)$, bubbles generate substantial volatility of 
market tightness and of the job finding rate. Not surprisingly, increasing the frequency of bubbles (higher $\Upsilon$ ) or the initial jump in value (higher $K$ ) makes it possible to generate higher volatility levels, close to the data. However, this comes at the cost of a volatility of the financial variables (firm value and the $\mathrm{P} / \mathrm{E}$ ratio) which is larger than in the data.

Table 4 - Simulated moments - Alternative wage rule

This table contains simulation results based on an alternative wage rule. The wage is computed based on the productivity and the labor market tightness at the time of job creation. Moments for all variables are computed using log deviations from an HP trend with smoothing parameter 100,000. Calibrated parameter values are summarized in Table 2. Bootstrapped standard errors are in parentheses. Standard errors are computed using 1,000 model solutions for 250 quarters. Persistence refers to the autocorrelation of the first differences for each variable.

\begin{tabular}{|c|c|c|c|c|c|c|c|}
\hline & \multicolumn{5}{|c|}{ Labor market moments } & \multicolumn{2}{|c|}{ Financial moments } \\
\hline & $u$ & $v$ & $\theta$ & $f$ & $x$ & $J$ & $J /(x-w)$ \\
\hline & \multicolumn{7}{|c|}{ Fundamental model (wages fixed with entry productivity and entry $\theta$ ) } \\
\hline St. dev. & $\begin{array}{c}0.055 \\
(0.005)\end{array}$ & $\begin{array}{c}0.086 \\
(0.005)\end{array}$ & $\begin{array}{c}0.124 \\
(0.010)\end{array}$ & $\begin{array}{c}0.071 \\
(0.007)\end{array}$ & $\begin{array}{c}0.020 \\
(0.001)\end{array}$ & $\begin{array}{c}0.054 \\
(0.004)\end{array}$ & $\begin{array}{c}0.066 \\
(0.007)\end{array}$ \\
\hline Autocorr. & $\begin{array}{c}0.923 \\
(0.011)\end{array}$ & $\begin{array}{c}0.607 \\
(0.037)\end{array}$ & $\begin{array}{c}0.836 \\
(0.022)\end{array}$ & $\begin{array}{c}0.834 \\
(0.023)\end{array}$ & $\begin{array}{c}0.849 \\
(0.020)\end{array}$ & $\begin{array}{c}0.838 \\
(0.021)\end{array}$ & $\begin{array}{c}0.912 \\
(0.018)\end{array}$ \\
\hline \multirow[t]{2}{*}{ Persistence } & $\begin{array}{c}0.286 \\
(0.037)\end{array}$ & $\begin{array}{l}-0.275 \\
(0.032)\end{array}$ & $\begin{array}{l}-0.084 \\
(0.036)\end{array}$ & $\begin{array}{l}-0.085 \\
(0.039)\end{array}$ & $\begin{array}{l}-0.046 \\
(0.035)\end{array}$ & $\begin{array}{c}-0.083 \\
(0.035)\end{array}$ & $\begin{array}{l}-0.054 \\
(0.040)\end{array}$ \\
\hline & \multicolumn{7}{|c|}{ Model with bubbles (wages fixed with entry productivity and entry $\theta$ ) } \\
\hline St. dev. & $\begin{array}{c}0.087 \\
(0.012)\end{array}$ & $\begin{array}{c}0.199 \\
(0.041)\end{array}$ & $\begin{array}{c}0.262 \\
(0.051)\end{array}$ & $\begin{array}{c}0.107 \\
(0.014)\end{array}$ & $\begin{array}{c}0.020 \\
(0.001)\end{array}$ & $\begin{array}{c}0.150 \\
(0.040)\end{array}$ & $\begin{array}{c}0.385 \\
(0.094)\end{array}$ \\
\hline Autocorr. & $\begin{array}{c}0.917 \\
(0.010)\end{array}$ & $\begin{array}{c}0.657 \\
(0.036)\end{array}$ & $\begin{array}{c}0.817 \\
(0.016)\end{array}$ & $\begin{array}{c}0.837 \\
(0.019)\end{array}$ & $\begin{array}{c}0.849 \\
(0.019)\end{array}$ & $\begin{array}{c}0.799 \\
(0.015)\end{array}$ & $\begin{array}{c}0.934 \\
(0.024)\end{array}$ \\
\hline Persistence & $\begin{array}{c}0.290 \\
(0.024)\end{array}$ & $\begin{array}{l}-0.225 \\
(0.022)\end{array}$ & $\begin{array}{l}-0.056 \\
(0.019)\end{array}$ & $\begin{array}{l}-0.049 \\
(0.029)\end{array}$ & $\begin{array}{l}-0.047 \\
(0.035)\end{array}$ & $\begin{array}{c}-0.061 \\
(0.015)\end{array}$ & $\begin{array}{c}0.378 \\
(0.159)\end{array}$ \\
\hline
\end{tabular}




\section{Table 5 - Volatility with alternative parameterizations}

This table contains simulated moments using alternative parameterizations and the baseline wage rule. The wage is computed based on the labor market tightness at the time of job creation and updated with productivity shocks. Each column corresponds to a different set of parameters. In each case, all parameters are at their baseline value (summarized in Table 2), except one. In the first column, we recall the simulated volatilities with the baseline calibration. In other columns, we vary respectively the probability that a bubbly state appears $(\Upsilon)$, the probability that it ends $(\Xi)$ and the initial jump in firm value when a bubbly state starts $(K)$. For each simulation, we report the standard deviation of the main variables. Moments for all variables are computed using log deviations from an HP trend with smoothing parameter 100,000 .

\begin{tabular}{|c|c|c|c|c|c|c|c|}
\hline & \multicolumn{7}{|c|}{ Volatility } \\
\hline & \multirow[t]{2}{*}{ Baseline } & \multicolumn{2}{|c|}{$\Upsilon$} & \multicolumn{2}{|c|}{$\Xi$} & \multicolumn{2}{|c|}{$K$} \\
\hline & & $1 / 24$ & $1 / 40$ & $1 / 4$ & $1 / 12$ & $1 \%$ & $3 \%$ \\
\hline$u$ & 0.069 & 0.076 & 0.063 & 0.055 & 0.068 & 0.052 & 0.079 \\
\hline$v$ & 0.179 & 0.199 & 0.162 & 0.169 & 0.152 & 0.119 & 0.223 \\
\hline$\theta$ & 0.232 & 0.257 & 0.210 & 0.207 & 0.204 & 0.157 & 0.285 \\
\hline$f$ & 0.082 & 0.090 & 0.075 & 0.067 & 0.082 & 0.062 & 0.094 \\
\hline$x$ & 0.020 & 0.020 & 0.020 & 0.020 & 0.020 & 0.020 & 0.020 \\
\hline$J$ & 0.153 & 0.170 & 0.138 & 0.145 & 0.124 & 0.096 & 0.195 \\
\hline$J /(x-w)$ & 0.356 & 0.398 & 0.323 & 0.263 & 0.428 & 0.298 & 0.399 \\
\hline
\end{tabular}




\section{Relation to the literature}

Our paper relates to three strands of previous work. A large literature has considered the possibility of rational bubbles in overlapping generation (OLG) models, along the tradition pioneered by Samuelson (1958) and Tirole (1985) in which bubbles improve allocative efficiency by reducing dynamically inefficient investment. Santos and Woodford (1997) study conditions under which rational asset price bubbles can arise in intertemporal competitive equilibria, while Weil (1990) shows how bubbles can be price-decreasing. In the presence of externalities, Olivier (2000) shows that bubbles in the stock market can increase long-term growth by fostering entrepreneurship. Recently, Martin and Ventura (2012) model bubbles driven by shocks to investor sentiment. Such bubbles can raise investment, in contrast with bubbles in the Samuelson-Tirole model. Bubbly states in our model arise because of shifts in the beliefs of some agents. Fahri and Tirole (2012) have studied the issue of bubbles in an OLG model with inefficient financial markets where investment is partly pledgeable. They prove an important result augmenting the scope of the existence of bubbles: a dynamically efficient economy can have bubbles, since the condition of a dynamically inefficient economy is no longer a necessary condition for the existence of a bubble. As they argue, this happens when "the social rate of return on internal funds exceeds that on borrowed funds; therefore, the social rate of return on investments is higher than the market interest rate when returns can be only imperfectly collateralized. As a result, bubbles are possible even when the economy is dynamically efficient." In contrast with fully rational models, bubbles in our case always become socially inefficient when they last for too long.

Second, the literature linking financial bubbles to labor market outcomes is surprisingly small. None of the above papers on bubbles discusses labor market outcomes. To our knowledge, only two related papers consider bubbles in search-and-matching economies. ${ }^{17}$

\footnotetext{
${ }^{17} \mathrm{~A}$ few recent papers relate pricing in financial markets to hiring decisions by firms, absent any bubble. Hall (2016) argues that recessions are associated with a high discount rate in the stock market. Expected profits from job creation are discounted more, so that job creation falls. Kilic and Wachter (2016) show that time-varying disaster risk can explain the joint behavior of stock market valuations and unemployment.
} 
Kocherlakota (2011) blends the OLG model of Samuelson (1958) with a matching model that does not satisfy the usual equilibrium job creation condition. In his model, the burst of bubbles does not affect unemployment when monetary policy is sufficiently accommodative - a result which differs from ours, since bubbly states in our model are necessarily characterized by allocative distortions, which are corrected in latent states. In Miao, Wang, and Xu (2016), credit constraints give rise to multiple equilibria, so that shifts in beliefs, not fundamentals, can create unemployment. Our model is closer to the Pissarides model (Pissarides, 1985; Mortensen and Pissarides, 1994), which we treat as a benchmark to characterize fundamental values. Labor market distortions are then expressed relative to this fundamental state. In contrast with both Kocherlakota (2011) and Miao, Wang, and Xu (2016), we also explore the quantitative ability of a matching model with bubbles to replicate the data. Finally, Cahuc and Challe (2012) study an OLG economy in which bubbles induce skilled workers to move away from the productive sector to the financial sector. Their model is consistent with numerous pieces of anecdotal evidence, for example about the striking growth of occupations in finance among Harvard graduates in the years leading up to the financial crisis (Goldin and Katz, 2008). An extension of our model to allow for multiple sectors could rationalize these facts.

Finally, this paper relates to a large body of research that proposes potential resolutions of the "unemployment volatility puzzle", highlighted by Shimer (2005). Among the proposed extensions to the Pissarides model are the introduction of wage rigidity (Hall, 2005) or the enrichment of the model with additional features such as on-the-job search or financial frictions (Wasmer and Weil, 2004). To generate a high volatility of labor market outcomes, Hagedorn and Manovskii (2008) propose an alternative calibration of the standard model, with a value of leisure close to that of labor, and a small labor share of surplus. Together, these features increase the sensitivity of firm profits to productivity shocks, which drives incentives to post vacancies. Mortensen (1999) models increasing returns to scale in production as an alternative source of multiple equilibria, which gives rise to unstable dynamics and limit cycles. Instead, we propose that the occurrence of stochastic bubbles in firm value can be a major source of unemployment volatility. 
A strong empirical connection between volatility in the labor and in the stock market supports this extension. The tight link between real and financial variables in our model does not arise from a financial accelerator mechanism (Kiyotaki and Moore, 1997). Volatility does not result from productivity shocks that are amplified, but from nonfundamental changes in the beliefs of some investors. Baker and Wurgler (2006) show that stock market bubbles are consistently associated with changes in investor sentiment.

\section{Conclusion}

Bubbles have been neglected in the search-and-macro literature, perhaps because of the lack of simple solution characterizing bubbly episodes. The resulting lack of volatility led macroeconomists to introduce additional sources of volatility and amplification, such as wage stickiness, high bargaining shares, and other modeling variants. While these efforts have significantly improved the understanding of the dynamics of labor frictions, the theoretical possibility of bubbles has not been part of the main accounts. We provide such a framework, with the simplest set of assumptions, that preserve rationality of individual decisions and are gentlemanly close $^{18}$ to the standard search approach. Our model has a source of wage rigidity, but preserves the most important flexibility of wages, the fact that entry wage depends on the current level of labor market tightness.

We characterize the distortions in firm value and market tightness that bubbles induce, and show that the usual Hosios efficiency condition is no longer satisfied. Our analysis rationalizes key stylized facts about bubbles, such as large deviations from trend in employment. Quantitatively, we show that introducing bubbles makes it possible to reconcile the matching model with important features of the data. It can explain the high volatility of labor market outcomes, which the standard model is not able to generate. It can also explain the high volatility of financial variables, such as the market value of firms. To sum up, in our model, volatility of both real and financial variables are two sides of the same coin, consistent with empirical evidence.

\footnotetext{
${ }^{18}$ We give credit to Victor Rios-Rull for this expression.
} 
Our model of bubbles can, and should, be extended along several dimensions. Preliminary work suggests that a multiple-sector extension can explain additional features of the data. In a two-sector model, the bubbly sector attracts workers from the stationary sector, even though relative productivity is not increasing. When the bubble bursts, frictional labor reallocation across sectors can create prolonged aggregate unemployment. Another promising avenue is the study of bubbles in models with industry-specific human-capital investments. In this case, bubbles induce workers to over-invest in skills that they can use in a bubbly state, but increase the cost of job-to-job transitions once the bubble bursts.

Another dimension left aside at this stage is the question of the regulatory instruments used to correct distortions induced by bubbles. Our discussion on efficiency is limited to that of the optimal share of workers in total surplus. Quantitatively, we show that the deviation from the Hosios rule is small in the latent state and at the inception of a bubbly state, but grows exponentially afterwards. Instruments such as a tax on wages, or on vacancies, or subsidies to non-employment could correct inefficiencies. However, understanding their effects would require a better integration of our model with monetary policy, along the lines of the search and money literature and of the growing literature on bubbles. 


\section{References}

Baker, M. and J. Wurgler (2006). Investor sentiment and the cross-section of stock returns. Journal of Finance 61, 1645-1680.

Baker, M. and J. Wurgler (2007). Investor sentiment in the stock market. Journal of Economic Perspectives 21, 129-151.

Barnichon, R. (2010). Building a composite Help-Wanted Index. Economic Letters 109, 175-178.

Blanchard, O. J. (1979). Speculative bubbles, crashes, and rational expectations. Economic Letters 3, 387-389.

Blanchard, O. J. and S. Fischer (1989). Lectures on macroeconomics. MIT Press.

Blanchard, O. J. and M. W. Watson (1982). Bubbles, rational expectations and financial markets. NBER Working Paper 945.

Brunnermeier, M. and S. Nagel (2004). Hedge funds and the technology bubble. Journal of Finance 59, 2013-2040.

Caballero, R. J. (2006). On the macroeconomics of asset shortages. Working paper.

Cahuc, P. and E. Challe (2012). Produce of speculate? Asset bubbles, occupational choices and efficiency. International Economic Review 53, 1005-1035.

Carvelho, V., A. Martin, and J. Ventura (2011). Bubbly business cycles. Working paper.

De Marzo, P., R. Kaniel, and I. Kremer (2007). Technological innovation and real investment booms and busts. Journal of Financial Economics 85, 735-754.

den Haan, W. J., G. Ramey, and J. Watson (2000). Job destruction and propagation of shocks. American Economic Review 90, 482-498.

Diba, B. T. and H. I. Grossman (1988). The theory of rational bubbles in stock prices. Economic Journal 98, 746-754.

Fahri, E. and J. Tirole (2012). Bubbly liquidity. Review of Economic Studies 79, 678-706. 
Goldin, C. and L. F. Katz (2008). Transitions: Career and family life cycles of the educational elite. Americann Economic Review: Papers $\&$ Proceedings 98, 363-369.

Hagedorn, M. and I. Manovskii (2008). The cyclical behavior of equilibrium unemployment and vacancies revisited. American Economic Review 98, 1692-1706.

Hall, R. E. (2005). Employment fluctuations with equilibrium wage stickiness. American Economic Review 95, 50-65.

Hall, R. E. (2016). High discounts and high unemployment. American Economic Review (forthcoming).

Hosios, A. J. (1990). On the efficiency of matching and related models of search and unemployment. Review of Economic Studies 57, 279-298.

Kilic, M. and J. A. Wachter (2016). Risk, unemployment, and the stock market: A rare-event-based explanation of labor market volatility. Working paper.

Kindleberger, C. (1978). Manias, Panics, and Crashes. Basic.

Kiyotaki, N. and J. Moore (1997). Credit cycles. Journal of Political Economy 105, $211-248$.

Kocherlakota, N. (2011). Bubbles and unemployment. Working paper.

Ljungqvist, A. and W. J. J. Wilhelm (2003). IPO pricing in the dot-com bubble. Journal of Finance 58, 723-752.

Martin, A. and J. Ventura (2012). Economic growth with bubbles. American Economic Review 102, 3033-3058.

Miao, J., P. Wang, and L. Xu (2016). Stock market bubbles and unemployment. Economic Theory 61, 273-307.

Mortensen, D. T. (1999). Equilibrium unemployment dynamics. International Economic Review 40, 889-914.

Mortensen, D. T. and C. A. Pissarides (1994). Job creation and job destruction in the theory of unemployment. Review of Economic Studies 61, 397-415. 
Ofek, E. and M. Richardson (2003). Dotcom mania: The rise and fall of internet stock prices. Journal of Finance 58, 1113-1137.

Olivier, J. (2000). Growth-enhancing bubbles. International Economic Review 41, 133152.

Pastor, L. and P. Veronesi (2006). Was there a NASDAQ bubble in the late 1990s? Journal of Financial Economics 81, 61-100.

Petrosky-Nadeau, N. and L. Zhang (2013). Unemployment crises. Working paper.

Pissarides, C. A. (1985). Short-run equilibrium dynamics of unemployment, vacancies and real wages. American Economic Review 75, 676-690.

Pissarides, C. A. (2000). Equilibrium unemployment theory. MIT Press.

Pissarides, C. A. (2009). The unemployment volatility puzzle: Is wage stickiness the answer? Econometrica 7\%, 1339-1369.

Samuelson, P. (1958). An exact consumption-loan model of interest with or without the social contrivance of money. Journal of Political Economy 66, 467-482.

Santos, M. S. and M. Woodford (1997). Rational asset pricing bubbles. Econometrica 65, $19-57$.

Shiller, R. (1981). Do stock prices move too much to be justified by subsequent changes in dividends? American Economic Review 71, 421-36.

Shiller, R. (2015). Irrational Exuberance. Princeton University Press.

Shimer, R. (2005). The cyclical behavior of equilibrium unemployment and vacancies. American Economic Review 95, 25-49.

Tauchen, G. (1986). Finite state Markov-chain approximations to univariate and vector autoregressions. Economic Letters 20, 177-181.

Tirole, J. (1982). On the possibility of speculation under rational expectations. Econometrica 50, 1163-1181. 
Tirole, J. (1985). Asset bubbles and overlapping generations. Econometrica 53, 14991528.

Wasmer, E. and P. Weil (2004). The macroeconomics of labor and credit market imperfections. American Economic Review 94, 944-963.

Weil, P. (1987). Confidence and the real value of money in an overlapping generations economy. Quarterly Journal of Economics 102, 1-22.

Weil, P. (1990). On the possibility of price decreasing bubbles. Econometrica 58, $1467-$ 1474. 


\section{Table 6 - Notation}

This table summarizes all notation from the model.

\begin{tabular}{|c|c|}
\hline Notation & Definition \\
\hline & Market tightness and value functions, by state \\
\hline$\theta^{0}$ & Steady state labor market tightness in the fundamental state \\
\hline$\theta^{L}$ & Steady state labor market tightness in the latent state \\
\hline$\theta_{\tau}^{B}$ & Labor market tightness in the bubbly state, when bubble has duration $\tau$ \\
\hline$J^{0}$ & Asset value of a filled vacancy in the fundamental state \\
\hline$J^{L}$ & Asset value of a filled vacancy in the latent state \\
\hline$J^{B}(\tau)$ & Asset value of a filled vacancy in the bubbly state, when bubble has duration $\tau$ \\
\hline $\begin{array}{l}J_{v}^{0} \\
J_{v}^{L} \\
J_{v}^{B}\end{array}$ & $\begin{array}{l}\text { Asset value of an unfilled vacancy in the fundamental state } \\
\text { Asset value of an unfilled vacancy in the latent state } \\
\text { Asset value of an unfilled vacancy in the bubbly state }\end{array}$ \\
\hline $\begin{array}{l}W^{L} \\
W^{B}\end{array}$ & $\begin{array}{l}\text { Asset value of employment in the latent state } \\
\text { Asset value of employment in the bubbly state }\end{array}$ \\
\hline \multirow[t]{2}{*}{$W_{u}^{B}$} & $\begin{array}{l}\text { Asset value of unemployment in the latent state } \\
\text { Asset value of unemployment in the bubbly state }\end{array}$ \\
\hline & Other parameters and variables \\
\hline$r$ & Risk-free rate \\
\hline$s$ & Separation rate \\
\hline$\Upsilon$ & Instantaneous probability that a bubbly state starts \\
\hline$\Xi$ & Instantaneous probability that a bubbly state ends \\
\hline$R=r+s+\Xi$ & Bubble growth rate \\
\hline$q(\theta)$ & Job filling rate \\
\hline$f(\theta)$ & Job finding rate \\
\hline$v$ & Number of vacant positions \\
\hline$n$ & Number of employed workers \\
\hline$u$ & Number of unemployed workers \\
\hline$m(v, u)$ & Matching function \\
\hline$\gamma$ & Posting costs \\
\hline$x$ & Instantaneous output flow \\
\hline$z$ & Value of leisure \\
\hline$w$ & Wage \\
\hline$\alpha$ & Wage bargaining power of workers \\
\hline$K$ & Jump in firm value when bubble starts \\
\hline$\Delta(\tau)$ & Difference $J^{B}(\tau)-J^{L}$ \\
\hline
\end{tabular}




\section{Appendix - For online publication}

\section{A Data}

This appendix provides additional details on both sectoral and aggregate data.

\section{A.1 Sectoral data}

Sectoral data is used to depict stock prices, employment and wages over the 1995-2005

period (i.e., five years before and after the 2000 crash of the technology bubble). We construct series as follows:

- Stock market indices: We obtain data at a daily frequency on the Nasdaq Composite Index from FRED (series id: NASDAQCOM) and on the Dow Jones Industrial Average from the Wall Street Journal.

- Employed workers in technology and other sectors: We obtain data on the total number of employed workers by industry (NAICS code) from the U.S. Bureau of Labor Statistics (series id: ce.data.01.CurrentSaesAE.txt), from 1995 to 2005. High-tech sectors are identified as in Ljungqvist and Wilhelm (2003), by SIC codes 3571, 3572, 3575, 3577, 3578 (computer hardware), 3661, 3663, 3669 (communications equipment), 3674 (electronics), 3812 (navigation equipment), 3823, 3825, 3826, 3827, 3829 (measuring and controlling devices), 4899 (communication services), and 7370, 7371, 7372, 7374, 7375, 7378, and 7379 (software). We convert SIC codes to relevant NAICS codes using the SIC-to-NAICS Crosswalk tables provided by NAICS Association.

- Hourly earnings in technology and other sectors: We obtain data on average hourly earnings of production and nonsupervisory employees by industry (NAICS code) from the U.S. Bureau of Labor Statistics, from 1995 to 2005. High-tech sectors are identified as described above. Wages are weighted by the number of employed workers in each sector. 


\section{A.2 Aggregate data}

We follow Shimer (2005) by using data starting in January 1951, which makes it possible to have consistent series for the main variables of the model. The sample period extends to December 2014. After this date, the measure of vacancies is no longer available. We construct series as follows:

- Unemployment $(u)$ : We obtain monthly data on the U.S. unemployment rate from FRED (Federal Reserve Economic Data, at the Federal Reserve Bank of St. Louis, series id: UNRATE). Primary data is constructed by the U.S. Bureau of Labor Statistics from the Current Population Survey (CPS), and seasonally adjusted.

- Vacancies $(v)$ : We use the Help-Wanted Index proposed by Barnichon (2010). It combines measures of print and online help-wanted advertising from the Conference Board (see also Petrosky-Nadeau and Zhang, 2013, for a discussion). From $v$ and $u$, labor market tightness is computed as $\theta=v / u$.

- Job finding rate $(f)$ : We follow Shimer (2005) and compute the job finding rate as $f_{t}=1-\left(u_{t+1}-u_{t+1}^{s}\right) / u_{t}$, where $u_{t+1}^{s}$ is the number of workers unemployed for less than one month in month $t+1$. From FRED, we obtain data on workers unemployed for less than five weeks (series id: UEMPLT5). The total number of unemployed workers is obtained by summing series UEMPLT5 + UEMP5TO14 + UEMP15T26 + UEMP27OV. Primary data is constructed by the U.S. Bureau of Labor Statistics from the CPS, and seasonally adjusted.

- Labor productivity $(x)$ : From FRED, we download the real output per person in the non-farm business sector, at a quarterly frequency (series id: PRS85006163). Primary data is constructed by the U.S. Bureau of Labor Statistics and seasonally adjusted.

- Firm market value $(J)$ : We use the S\&P Composite Stock Price Index, obtained from Robert Shiller's website, http://www.econ.yale.edu/ shiller/data.htm (see also Shiller, 2015), at a monthly frequency. 
- Price-earning $(\mathbf{P} / \mathbf{E})$ ratio $(J /(x-w))$ : Use the cyclically adjusted $\mathrm{P} / \mathrm{E}$ ratio, obtained from Robert Shiller's website (see above). Cyclical adjustment is obtained by averaging real earnings over a 10-year period. Data is available at a monthly frequency from January 1871 to March 2016. 


\section{B Derivations of model equations}

We provide details on the derivation of some of the model equations.

\section{B.1 Derivation of Equation (17)}

The derivation of Equation (17) starts from the value of $\Delta(\tau)$ in Equation (16), and

$$
\begin{aligned}
\Delta(\tau) & =\frac{R}{r+s} K e^{R \tau}-\frac{\Xi}{r+s} \Delta(\tau)-\frac{\Upsilon}{r+s} \Delta(0) \\
\Leftrightarrow \Delta(\tau) \frac{R}{r+s}+\frac{\Upsilon}{r+s} \Delta(0) & =\frac{R}{r+s} K e^{R \tau} \\
\Leftrightarrow \Delta(\tau)+\frac{\Upsilon}{R} \Delta(0) & =K e^{R \tau} \\
\Rightarrow \Delta(0)+\frac{\Upsilon}{R} \Delta(0) & =K \\
\Rightarrow \Delta(\tau)-\Delta(0) & =K\left[e^{R \tau}-1\right] \\
\Leftrightarrow \Delta(0) & =K \frac{R}{R+\Upsilon},
\end{aligned}
$$

where calculations also make Equation (18) appear.

\section{B.2 Derivation of Equation (27)}

From Equation (24), together with Equation (5), and eliminating the denominator $(r+$ $s+\Upsilon)$, one obtains

$$
(r+s+\Upsilon)\left(W^{L}-W_{u}^{L}\right)=w-r W_{u}+\Upsilon\left(W^{B}(0)-W_{u}^{L}\right)
$$

which, together with the Nash-bargaining equation, yields

$$
w=(1-\alpha) r W_{u}^{L}-(1-\alpha) \Upsilon\left(W^{B}(0)-W_{u}^{L}\right)+\alpha x+\alpha \Upsilon J^{B}(0) .
$$

Observing that

$$
r W_{u}^{L}=z+\frac{\alpha}{1-\alpha} \theta^{L} \gamma+\Upsilon\left(W_{u}^{B}(0)-W_{u}^{L}\right)
$$


and after some calculation, one obtains

$$
\begin{aligned}
w^{L} & =(1-\alpha) z+\alpha\left(x+\theta^{L} \gamma\right)-(1-\alpha) \Upsilon\left(W^{B}(0)-W_{u}^{L}\right)+\alpha \Upsilon J^{B}(0)+(1-\alpha) \Upsilon\left(W_{u}^{B}(0)-W_{u}^{L}\right) \\
& =(1-\alpha) z+\alpha\left(x+\theta^{L} \gamma\right)+(1-\alpha) \Upsilon\left(-W^{B}(0)+W_{u}^{B}(0)\right)+\alpha \Upsilon J^{B}(0)
\end{aligned}
$$

Assume that wages are renegotiated when the bubble appears, then

$$
(1-\alpha) \Upsilon\left(W^{B}(0)-W_{u}^{B}(0)\right)=\alpha \Upsilon J^{B}(0)
$$

from which it follows that the wage equals

$$
w^{L}=(1-\alpha) z+\alpha\left(x+\theta^{L} \gamma\right)
$$

\section{B.3 Wages and entry in the semi-flexible case}

We first show why we cannot allow $w^{B}\left(0, \tau^{\prime}\right)$ to evolve over time if one wants the value of firms to grow at exponential rate. To prove it by contradiction, assume that there exists a constant $\omega$ such that

$$
w^{B}\left(0, \tau^{\prime}\right)=w^{B}(0,0)+\omega\left(e^{R \tau^{\prime}}-1\right) .
$$

Given that

$$
R J^{B}\left(0, \tau^{\prime}\right)=x-w^{B}\left(0, \tau^{\prime}\right)+\Xi J^{L}+\frac{\partial J^{B}}{\partial t}
$$

it follows that a solution is still

$$
J^{B}\left(0, \tau^{\prime}\right)=a+K e^{R \tau^{\prime}}
$$

with

$$
R a+R K e^{R \tau^{\prime}}=x-w^{B}(0,0)-\omega\left(e^{R \tau^{\prime}}-1\right)+\Xi J^{L}+b K e^{R \tau},
$$


which implies that $\omega=0$ and

$$
a=\frac{x-w^{B}(0,0)+\Xi J}{R},
$$

so that

$$
w^{B}\left(0, \tau^{\prime}\right)=w^{B}(0,0)
$$

The wage is therefore constant after initial negotiation.

Next, the wage can be replaced into the free-entry condition to get Equation (30). Further, from

$$
J_{\pi}^{B}(\tau, \tau)=\frac{(x-z)(1-\alpha)-\alpha \gamma \theta_{\tau}^{B}+\Xi J_{\pi}}{R}+K_{J} e^{R \tau},
$$

Multiplying by $R$ and dividing by $(r+s)$, yields

$$
J_{\pi}^{B}=\frac{(x-z)(1-\alpha)-\alpha \gamma \theta_{\tau}^{B}}{r+s}+\frac{\Xi}{r+s}\left(J_{\pi}^{L}-J_{\pi}^{B}\right)+\frac{R}{r+s} K_{J} e^{R \tau},
$$

or

$$
J_{\pi}^{B}=\frac{(x-z)(1-\alpha)-\alpha \gamma \theta_{\tau}^{B}}{r+s}+\frac{\Xi}{r+s}(-\Delta(\tau))+\frac{R}{r+s} K_{J} e^{R \tau} .
$$

Simplifying using: $\Delta(\tau)-\Delta(0)=K_{J}\left[e^{R \tau}-1\right]$ and

$$
\Delta(0)=K_{J} \frac{R}{R+\Upsilon}
$$

yields

$$
J_{\pi}^{B}=\frac{(x-z)(1-\alpha)-\alpha \gamma \theta_{\tau}^{B}}{r+s}-\frac{\Xi}{r+s} K\left[e^{R \tau}-1\right]+\frac{R}{r+s} K_{J} e^{R \tau}-\frac{\Xi}{r+s} \Delta(0) .
$$

After a few additional calculations,

$$
\begin{gathered}
J_{\pi}^{B}=\frac{(x-z)(1-\alpha)-\alpha \gamma \theta_{\tau}^{B}}{r+s}+e^{R \tau} K\left(-\frac{\Xi}{r+s}+\frac{R}{r+s}\right)+\frac{\Xi}{r+s} K-\frac{\Xi}{r+s} \Delta(0), \\
J_{\pi}^{B}=\frac{(x-z)(1-\alpha)-\alpha \gamma \theta_{\tau}^{B}}{r+s}+e^{R \tau} K+\frac{\Xi}{r+s} K-\frac{\Xi}{r+s} \Delta(0),
\end{gathered}
$$




$$
J_{\pi}^{B}=\frac{(x-z)(1-\alpha)-\alpha \gamma \theta_{\tau}^{B}}{r+s}+e^{R \tau} K+\frac{\Xi}{r+s} K\left(\frac{\Upsilon}{R+\Upsilon}\right)
$$

such that one obtains Equation (32).

\section{B.4 Wages in the fully flexible case}

Starting from definitions of the workers' asset equations,

$$
\begin{gathered}
r W^{B}=w+s\left(W_{u}^{B}-W^{B}\right)+\Xi\left(W^{L}-W^{B}\right)+\frac{\partial W^{B}}{\partial t}, \\
r W_{u}^{B}=z+\theta^{B} q\left(\theta^{B}\right)\left(W^{B}-W_{u}^{B}\right)+\Xi\left(W_{u}^{L}-W_{u}^{B}\right)+\frac{\partial W_{u}^{B}}{\partial t},
\end{gathered}
$$

and from

$$
w=\operatorname{argmax}\left(W^{B}\left(w^{B}(\tau)-W_{u}^{B}(\tau)\right)^{\alpha}\left(J^{B}\left(w^{B}(\tau), \tau\right)\right)^{1-\alpha},\right.
$$

one obtains

$$
R\left(W^{B}-W_{u}^{B}\right)=w-r W_{u}^{B}+\Xi\left(W^{L}-W_{u}^{B}\right)+\left(\frac{\partial W^{B}}{\partial t}-\frac{\partial W_{u}^{B}}{\partial t}\right)+\frac{\partial W_{u}^{B}}{\partial t}
$$

while

$$
R J^{B}=x-w+\Xi J^{L}+\frac{\partial J^{B}}{\partial t}
$$

The solution must follow

$$
\left(w-r W_{u}^{B}+\Xi\left(W^{L}-W_{u}^{B}\right)+\left(\frac{\partial W^{B}}{\partial t}-\frac{\partial W_{u}^{B}}{\partial t}\right)+\frac{\partial W_{u}^{B}}{\partial t}\right)(1-\alpha)=\alpha\left(x-w+\Xi J^{L}+\frac{\partial J^{B}}{\partial t}\right)
$$

or

$$
\left(w-r W_{u}^{B}+\Xi\left(W-W_{u}^{B}\right)+\frac{\partial W_{u}^{B}}{\partial t}\right)(1-\alpha)=\alpha\left(x-w+\Xi J^{L}\right)
$$

or

$$
w=\alpha\left(x+\Xi J^{L}\right)+\left(r W_{u}^{B}-\Xi\left(W^{L}-W_{u}^{L}+W_{u}^{L}-W_{u}^{B}\right)-\frac{\partial W_{u}^{B}}{\partial t}\right)(1-\alpha)
$$


or, eliminating $\alpha \Xi J^{L}$ by $\Xi\left(W^{L}-W_{u}^{L}\right)(1-\alpha)$, using the bargaining equation in the latent state,

$$
w=\alpha(x)+\left(r W_{u}^{B}-\Xi\left(W_{u}^{L}-W_{u}^{B}\right)-\frac{\partial W_{u}^{B}}{\partial t}\right)(1-\alpha)
$$

Next, using

$$
r W_{u}^{B}-\frac{\partial W_{u}^{B}}{\partial t}=z+\theta^{B} q\left(\theta^{B}\right)\left(W^{B}-W_{u}^{B}\right)+\Xi\left(W_{u}^{L}-W_{u}^{B}\right)
$$

we have

$$
w=\alpha(x)+\left(z+\theta^{B} q\left(\theta^{B}\right)\left(W^{B}-W_{u}^{B}\right)+\Xi\left(W_{u}^{L}-W_{u}^{B}\right)-\Xi\left(W_{u}^{L}-W_{u}^{B}\right)\right)(1-\alpha),
$$

or

$$
w=\alpha(x)+\left(z+\theta^{B} q\left(\theta^{B}\right)\left(W^{B}-W_{u}^{B}\right)\right)(1-\alpha)
$$

and lastly using $W^{B}-W_{u}^{B}=J^{B} \alpha /(1-\alpha)=\gamma / q\left(\theta^{B}\right)$, yields

$$
w=\alpha\left(x+\theta^{B} \gamma\right)+z(1-\alpha)
$$




\section{Bubbles in firm value: A discrete-time illustration}

We illustrate how bubbles in firm value can arise within the standard matching model. Consider single-worker firms in discrete time. A firm has either one worker or none, so that a bubble in firm value is a bubble in the value of a filled vacancy. Denote $J_{\pi t}$ and $J_{v t}$, respectively, the asset values of filled and unfilled vacancies at date $t$. A filled vacancy yields a per-period output $x_{t}$ and gets paid a wage $w_{t}$. The return $S_{t}$ on a filled vacancy between $t$ and $t+1$ (alternatively, the per-period return of holding the firm in a portfolio) is

$$
S_{t}=\frac{(1+r)\left(x_{t}-w_{t}\right)+(1-s) \mathbb{E}\left[J_{\pi t+1}\right]-J_{\pi t}}{J_{\pi t}},
$$

where $x_{t}-w_{t}$ is the per-period profit flow ("dividend" in an asset pricing equation) and $(1-s) \mathbb{E}\left[J_{\pi t+1}\right]-J_{\pi t}$ is the per-period change in a filled vacancy value ("capital gain" in an asset pricing equation). $(1-s) \mathbb{E}\left[J_{\pi t+1}\right]$ is the expected job value at the beginning of date $t+1$, where we recognize that a job gets destroyed with a per-period probability $s$, so that its value falls to $J_{v t+1}=0 .{ }^{19}$ Profits $x_{t}-w_{t}$ are received at the beginning of date $t$, and can be re-invested until date $t+1$ at the risk-free rate $r$.

In efficient markets, a risk-neutral investor is indifferent between investing in the firm and in the risk-free asset,

$$
\mathbb{E}_{t}\left[S_{t}\right]=r
$$

Replacing and rearranging yields the first-order difference equation

$$
J_{\pi t}=x_{t}-w_{t}+\frac{1-s}{1+r} \mathbb{E}_{t}\left[J_{\pi t+1}\right]
$$

a particular solution of which is

$$
J_{\pi t}^{0}=\sum_{i=0}^{\infty}\left(\frac{1-s}{1+r}\right)^{i} \mathbb{E}_{t}\left[x_{t+i}-w_{t+i}\right]
$$

In this case, the value of a filled vacancy is its fundamental value, that is, the present

\footnotetext{
${ }^{19} \mathrm{~A}$ free-entry condition for vacancies is required for $J_{v t+1}=0$ to hold.
} 
discounted value of the stream of profits it generates until the job gets destroyed (at rate $s$ ). The fundamental value is not the only solution, however. General solutions to (48) are of the form

$$
J_{\pi t}=\sum_{i=0}^{\infty}\left(\frac{1-s}{1+r}\right)^{i} \mathbb{E}_{t}\left[x_{t+i}-w_{t+i}\right]+B_{t}
$$

with

$$
\mathbb{E}_{t}\left[B_{t+1}\right]=\frac{1+r}{1-s} B_{t}
$$

In Equation (49), the value of a filled job is the sum of its fundamental value plus a bubble component, $J_{\pi t}=J_{\pi t}^{0}+B_{t}$. As long as they satisfy Equation (50), bubbles can take any form (see Blanchard and Watson, 1982). One interesting case is that of a stochastic bubble that bursts with a constant per-period probability $\Xi$,

$$
B_{t+1}=\left\{\begin{array}{rll}
\frac{1+r}{(1-s)(1-\Xi)} B_{t} & \text { with probability } & 1-\Xi \\
0 & \text { with probability } & \Xi
\end{array}\right.
$$

To be sustainable, a stochastic bubble must grow at a rate higher than $r$, to compensate holders of the bubble for the fact that it may burst with probability $\Xi$, and that the job can be terminated with probability $s$. We construct our baseline model using this specification. This simple case illustrates that bubbles in firm value are part of the set of solutions to the standard matching model. 


\section{Alternative models of bubbles}

In this appendix, we introduce alternative models of bubbles. First, transitions between the latent and the bubbly states can be tied to realizations of the productivity shock $x$. Second, the probability that a bubble bursts can increase over time.

\section{D.1 Transitions across states driven by productivity shocks}

We now assume that the transition between latent and bubbly is tied to realizations of aggregate productivity $x$. There is only one generic Poisson shock with parameter $\lambda$, still drawn from the distribution of productivity characterized by c.d.f. $G(x)$ with support $\left[x_{\min }, x_{\max }\right]$. We maintain the assumption that the $x_{\min }$ is high enough to ensure that the firm is not destroyed when it is realized.

This productivity process provides a justification for the appearance and disappearance of bubbly states. Empirically, there is ample evidence that bubbles appear at times of technological breakthroughs (De Marzo et al., 2007). It can be assumed that transitions $\Upsilon$ and $\Xi$ coincide with changes in aggregate productivity. Hence, the apparition of the bubbly state is rationalized by the occurrence of a high productivity shock, which induces some agents to change expectations about future capital gains. In this case, $\Upsilon=\lambda \cdot\left(1-G\left(B^{+}\right)\right)$, where $B^{+}$is the productivity threshold leading to the appear-

ance of a bubbly state. Conversely, a transition back to the latent state is triggered at rate $\Xi=\lambda \cdot G\left(B^{-}\right)$, where $B^{-}$is low productivity threshold inducing agents to revise their expectations. The limit case in which bubbly expectations never emerge is when $1-G\left(B^{+}\right)=0$.

The value of a filled vacancy in the latent state is

$$
(r+s+\lambda) J^{L}(x)=x-w+\lambda \cdot \int_{x_{\min }}^{B^{+}} J^{L}\left(x^{\prime}\right) \mathrm{d} G\left(x^{\prime}\right)+\lambda \cdot \int_{B^{+}}^{x_{\max }} J^{B}\left(\tau=0, x^{\prime}\right) \mathrm{d} G\left(x^{\prime}\right)
$$

while it solves, in the bubbly state,

$$
(r+s+\lambda) J^{B}(\tau, x)=x-w+\lambda \cdot \int_{x_{\min }}^{B^{-}} J^{L}\left(x^{\prime}\right) \mathrm{d} G\left(x^{\prime}\right)+\lambda \cdot \int_{B^{-}}^{x_{\max }} J^{B}\left(\tau, x^{\prime}\right) \mathrm{d} G\left(x^{\prime}\right)+\frac{\partial J^{B}}{\partial t} .
$$


We postulate here the existence of solution of the form $a(x+b)+K e^{g \tau}$, where the solution grows exponentially at a constant rate $g$ between two productivity changes. It is easily verified that $g=r+s+\lambda \cdot G\left(B^{-}\right)=r+s+\Xi$, as before, and that $a=(r+s+\lambda)^{-1}$. Similarly, looking for linear solutions for $J^{L}(x)=a^{\prime}\left(x+b^{\prime}\right)$, one easily verified that $a^{\prime}=a=(r+s+\lambda)^{-1}$. The constant terms $b^{\prime}$ and $b$ incorporate the thresholds $B^{+}$and $B^{-}$, as well as the support of $G(x)$. Since they do not bring additional intuition, we do not make them explicit.

\section{D.2 Rising probability of the explosion of a bubble}

Alternatively, the probability that the bubbly state ends, $\Xi$, can be time-varying. In this case, $\Xi$ is a function of the duration of the bubbly state, $\tau$. This case has previously been discussed in Blanchard (1979).

\section{D.2.1 General solution}

The differential equation associated with this problem is

$$
[r+\mathrm{s}+\Xi(\tau)] J^{B}(\tau)=x-w+\Xi(\tau) J^{L}+\frac{\partial J^{B}}{\partial t}
$$

while it is still the case that

$$
J^{L}=\frac{x-w+\Upsilon J^{B}(0)}{r+s+\Upsilon}=\frac{\gamma}{q\left(\theta^{L}\right)}
$$

Generalizing the solution shown before, one postulates solutions satisfying

$$
[r+\mathrm{s}+\Xi(\tau)] J^{B}(\tau)=x-w+\Xi J^{L}+[r+\mathrm{s}+\Xi(\tau)] K(\tau) e^{[r+\mathrm{s}+\Xi(\tau)] \tau}
$$


The above equation can be differentiated under constant wages and productivity. We show that there is a function $K(\tau)$ linked to any time-varying function of $\Xi(\tau)$. It satisfies

$$
\begin{array}{r}
{[r+\mathrm{s}+\Xi(\tau)]\left[\frac{\partial J^{B}}{\partial t}-[r+\mathrm{s}+\Xi(\tau)] K(\tau) e^{[r+\mathrm{s}+\Xi(\tau)] \tau}\right]+\Xi^{\prime}(\tau) J^{B}(\tau)} \\
=\Xi^{\prime}(\tau) J^{L}+\Xi^{\prime}(\tau) K(\tau) e^{[r+\mathrm{s}+\Xi(\tau)] \tau}+[r+\mathrm{s}+\Xi(\tau)] K^{\prime}(\tau) e^{[r+\mathrm{s}+\Xi(\tau)] \tau} \\
\Leftrightarrow[r+\mathrm{s}+\Xi(\tau)]\left[\frac{\partial J^{B}}{\partial t}-(r+s+\Xi(\tau)) J^{B}(\tau)-\left(x-w+\Xi(\tau) J^{L}\right)\right]+\Xi^{\prime}(\tau) J^{B}(\tau) \\
=\Xi^{\prime}(\tau) J+\Xi^{\prime}(\tau) K(\tau) e^{[r+\mathrm{s}+\Xi(\tau)] \tau}+[r+\mathrm{s}+\Xi(\tau)] K^{\prime}(\tau) e^{[r+\mathrm{s}+\Xi(\tau)] \tau} \\
\Leftrightarrow \Xi^{\prime}(\tau)\left[J^{B}(\tau)-J^{L}-K(\tau) e^{[r+\mathrm{s}+\Xi(\tau)]}\right]=[r+\mathrm{s}+\Xi(\tau)] K^{\prime}(\tau) e^{[r+\mathrm{s}+\Xi(\tau)] \tau} \\
\Leftrightarrow \Xi^{\prime}(\tau)\left[\frac{x-w-(r+s) J^{L}}{r+\mathrm{s}+\Xi(\tau)}\right]=[r+\mathrm{s}+\Xi(\tau)] K^{\prime}(\tau) e^{[r+\mathrm{s}+\Xi(\tau)] \tau} \\
\Leftrightarrow \frac{\Xi^{\prime}(\tau)}{[r+\mathrm{s}+\Xi(\tau)]^{2}}\left[x-w-(r+s) J^{L}\right] e^{-(r+s+\Xi) \tau}=K^{\prime}(\tau) .
\end{array}
$$

The solution to $K(\tau)$ is given by:

$$
\frac{k_{J}(\tau)-K(0)}{x-w-(r+s) J}=\int_{0}^{T}\left[\frac{\Xi^{\prime}(\tau)}{[r+\mathrm{s}+\Xi(\tau)]^{2}} e^{-[r+\mathrm{s}+\Xi(\tau)] \tau}\right] d t .
$$

The generic problem is to find an explicit solution for

$$
\int_{0}^{T} H(\tau) d t
$$

where

$$
H(\tau)=\frac{\Xi^{\prime}(\tau)}{[r+\mathrm{s}+\Xi(\tau)]^{2}} e^{-[r+\mathrm{s}+\Xi(\tau)] \tau} .
$$


Equation (51) can be integrated, using the form $\int_{0}^{T} f(\tau) G(\tau) d t=[F(\tau) G(\tau)]_{0}^{T}-\int_{0}^{T} F(\tau) g(\tau) d t$, where

$$
\begin{aligned}
f(\tau) & =\frac{\Xi^{\prime}(\tau)}{[r+\mathrm{s}+\Xi(\tau)]^{2}}, \\
F(\tau) & =\frac{1}{[r+\mathrm{s}+\Xi(\tau)]}, \\
G(\tau) & =e^{-[r+\mathrm{s}+\Xi(\tau)] \tau}, \\
g(\tau) & =-[r+\mathrm{s}+\Xi(\tau)] e^{-[r+\mathrm{s}+\Xi(\tau)] \tau}+\Xi^{\prime}(\tau) e^{-(r+s+\Xi(\tau)) \tau},
\end{aligned}
$$

which leads to:

$$
\frac{k_{J}(\tau)-K(0)}{x-w-(r+s) J}=[F(\tau) G(\tau)]_{0}^{T}-\int_{0}^{T}\left[-e^{-[r+\mathrm{s}+\Xi(\tau)] \tau}+\frac{\Xi^{\prime}(\tau)}{r+\mathrm{s}+\Xi(\tau)} e^{-[r+\mathrm{s}+\Xi(\tau)] \tau}\right] d t
$$

\section{D.2.2 Specific cases}

We derive three special cases by formulating assumptions on the functional form $\Xi(\tau)$.

First, assume a function $\Xi(\tau)$ such that

$$
\begin{gathered}
\Xi(\tau)=e^{(r+\mathrm{s}+\Xi(\tau)) t}, \\
\Leftrightarrow \log (\Xi(\tau))=(r+\mathrm{s}+\Xi(\tau)) t
\end{gathered}
$$

so that

$$
\Xi^{\prime}(\tau)(1-t \Xi(\tau))=\Xi(\tau)(r+\mathrm{s}+\Xi(\tau))
$$

Thus,

$$
\begin{aligned}
\frac{\Xi^{\prime}(\tau)}{[r+\mathrm{s}+\Xi(\tau)]^{2}} e^{-[r+\mathrm{s}+\Xi(\tau)] \tau} & =\frac{\Xi(\tau)(r+\mathrm{s}+\Xi(\tau))}{[r+\mathrm{s}+\Xi(\tau)]^{2}(1-t \Xi(\tau))} e^{-[r+\mathrm{s}+\Xi(\tau)] \tau} \\
& =\frac{1}{[r+\mathrm{s}+\Xi(\tau)](1-\tau \Xi(\tau))} .
\end{aligned}
$$


A second special case is one in which $\Xi(\tau)=\Xi_{0}-a / t$, so that

$$
H(\tau)=\frac{a / t^{2}}{\left[r+\mathrm{s}+\Xi_{0}-a / t\right]^{2}} e^{-\left[r+\mathrm{s}+\Xi_{0}\right] \tau} e^{-a} .
$$

Finally, a third special case is with $\Xi(\tau)=\Xi_{0} e^{a t}$, so that

$$
H(\tau)=\frac{\Xi_{0} a}{[r+\mathrm{s}+\Xi(\tau)]^{2}} e^{-[r+\mathrm{s}+\Xi(\tau)-a] \tau} .
$$

